\title{
Urban energy concept \\ Solar district heating \\ Methodology and tools
}

Technical Report of IEA SHC Task 52, subtask B -

Methodologies, Tools and Case studies for Urban Energy concepts

Authors: Martin Joly (Sorane, $\mathrm{CH}$ ), Paul Bourdoukan (Sorane, $\mathrm{CH}$ ), JanBleicke Eggers (ISE, DE), Martin Andersen (SERC, SE), Chris Bales (SERC, $\mathrm{SE}$ ), Gabriel Ruiz (CREM, CH), Daniel Trier (Planenergi, DK), Christine Weber (BKW, CH), Sebastian Herkel (ISE, DE)

Sorane SA

Chemin des Saugettes 1

1024 Ecublens

Switzerland

Ecublens, 29st March 2016

Review: $20^{\text {st }}$ February 2018 


\section{IEA Solar Heating and Cooling Programme (IEA SHC)}

The Solar Heating and Cooling Technology Collaboration Programme was founded in 1977 as one of the first multilateral technology initiatives ("Implementing Agreements") of the International Energy Agency. Its mission is "to enhance collective knowledge and application of solar heating and cooling through international collaboration to reach the goal set in the vision of solar thermal energy meeting $50 \%$ of low temperature heating and cooling demand by 2050 .

The members of the IEA SHC collaborate on projects (referred to as "Tasks") in the field of research, development, demonstration (RD\&D), and test methods for solar thermal energy and solar buildings.

A total of 61 projects have been initiated, 53 of which have been completed. Research topics include:

- $\quad$ Solar Space Heating and Water Heating (Tasks 14, 19, 26, 44, 54)

- Solar Cooling (Tasks 25, 38, 48, 53)

- Solar Heat or Industrial or Agricultural Processes (Tasks 29, 33, 49)

- $\quad$ Solar District Heating (Tasks 7, 45, 55)

- $\quad$ Solar Buildings/Architecture/Urban Planning (Tasks 8, 11, 12, 13, 20, 22, 23, $28,37,40,41,47,51,52,56,59)$

- $\quad$ Solar Thermal \& PV (Tasks 16, 35, 60)

- $\quad$ Daylighting/Lighting (Tasks 21, 31, 50, 61)

- Materials/Components for Solar Heating and Cooling (Tasks 2, 3, 6, 10, 18, 27, 39)

- $\quad$ Standards, Certification, and Test Methods (Tasks 14, 24, 34, 43, 57)

- $\quad$ Resource Assessment (Tasks 1, 4, 5, 9, 17, 36, 46)

- $\quad$ Storage of Solar Heat (Tasks 7, 32, 42, 58)

In addition to the project work, there are special activities:

$>\quad$ SHC International Conference on Solar Heating and Cooling for Buildings and Industry

Solar Heat Worldwide - annual statistics publication

$>\quad$ Memorandum of Understanding - working agreement with solar thermal trade organizations

Workshops and seminars

\section{Country Members}

\begin{tabular}{lll} 
Australia & France & Spain \\
Austria & Germany & Sweden \\
Belgium & Italy & Switzerland \\
Canada & Mexico & Turkey \\
China & Netherlands & Portugal \\
Denmark & Norway & United Kingdom \\
European Commission & Slovakia & South Africa \\
\hline Rev. 2018-06-15, Sorane SA. M. Joly et al & &
\end{tabular}




\section{Sponsor Members}

European Copper Institute

International Solar Energy Society - ISES

ECREEE

\section{RCREEE}

Gulf Organization for Research and Development

For more information on the IEA SHC work, including many free publications, please visit www.iea-shc.org

The contents of this report do not necessarily reflect the viewpoints or policies of the International Energy Agency (IEA) or its member countries, the IEA Solar Heating and Cooling Technology Collaboration Programme (SHC TCP) members or the participating researchers. 


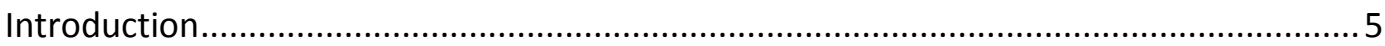

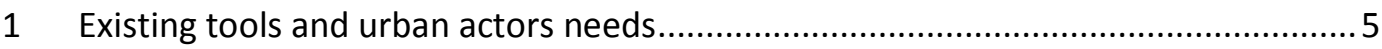

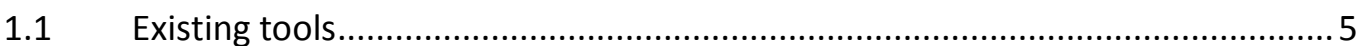

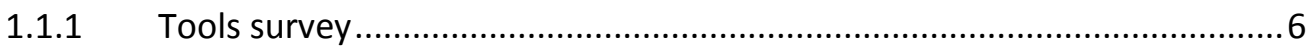

1.2 Assessment of the needs of urban actors .................................................... 7

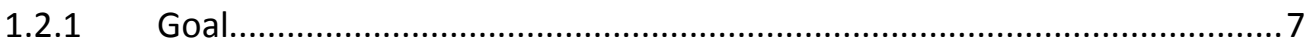

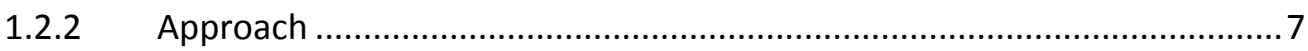

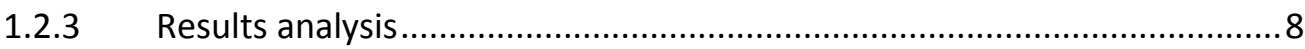

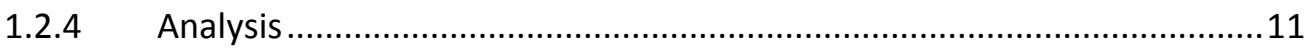

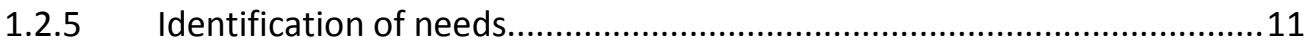

2 Development of a methodology to meet the needs of urban actors ....................... 12

2.1 Indicators and boundary conditions............................................................ 14

2.2 Decision path - from boundary conditions to the solar energy systems.......... 16

2.2.1 Boundary conditions............................................................................

2.2.2 Questions allowing to progress in the tree ...........................................16

2.2.3 Classification according to given energy system ....................................17

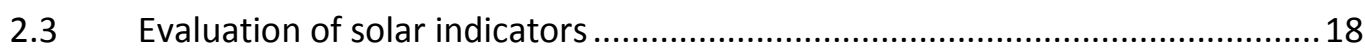

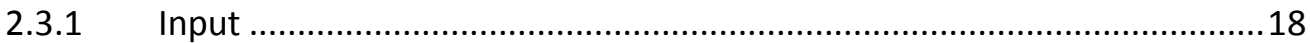

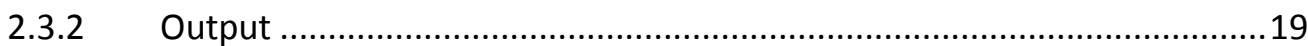

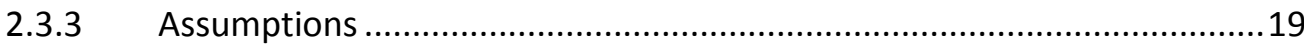

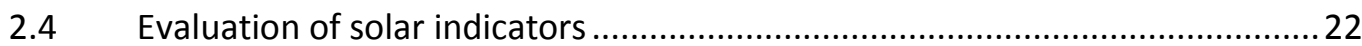

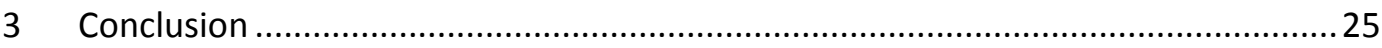

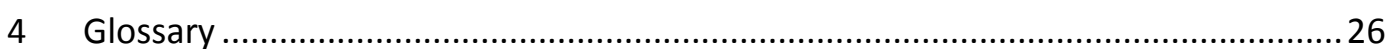

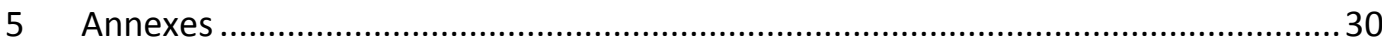

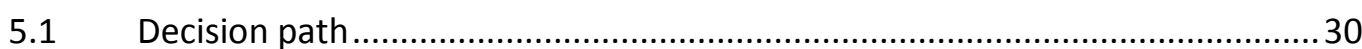

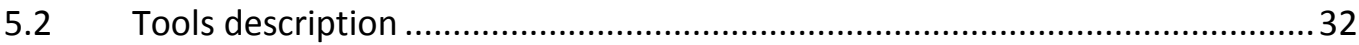

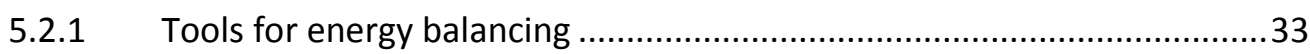

5.2.2 Tools for thermal, electrical or hydraulic simulations...............................38

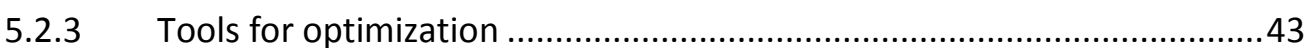

5.2.4 Others : GIS, tool frameworks, co-simulation platforms..........................45

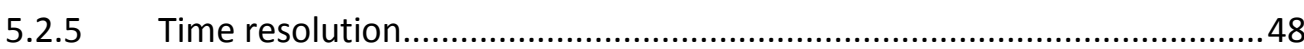




\section{Introduction}

The task 52 of the IEA solar heating and cooling program investigates the future role of solar thermal in urban energy system. This report summaries the different achievements of the subtask B focused on Methodologies, Tools and Case studies for Urban Energy concepts. In the first chapter, we will present the preliminary studies made on existing tools and on the assessment of the needs of urban actors. These studies were used as a base to build a new methodology. In the second chapter, we present a methodology to guide stakeholders in their different choices when projecting a solar district heating in urban environment. The case studies analysis is presented in a separated report ${ }^{1}$.

\section{Existing tools and urban actors needs}

\subsection{Existing tools}

Nowadays a lot of tools and model exist to simulate energy flux. For example, they are useful to estimate the annual solar gains, the building heat demand, the behaviour of complex transient system or the annual cost or the optimisation of national energy system. This domain was already studied and many publications are present in the literature. In 2006, S. Jebaraj2 already made a reviewing of various emerging issues related to the energy modelling. Based on this work, D. Connolly ${ }^{3}$ and B. Crawley ${ }^{4}$ published quite exhaustive review of existing simulation programs. In these papers, authors were aware that no ideal energy tool exists. However, these reviews were useful to provide information necessary to select the suitable energy tool.

More recently, researchers worked on complex system such as entire urban district composed of buildings, plants and storages. This coupled building, plant and heat simulation is necessary to solve the problem of time and space dependant situation. In his work, Huber et al. ${ }^{5}$ shows that such complex system overstress a current standard simulation tool. In order to overpass this problem, he develop a specific tool using co-simulation. This approach was also applied by D. Thomas ${ }^{6}$ who used this method to improve the accuracy of both Design Performance Viewer (DPV) and the CitySim urban simulation engine.

1 TECHNOLOGY AND DEMONSTRATORS - Technical Report Subtask B - Part B3, F. Mauthner, M. Joly and P. Bourdoukan, 2017

2 Jebaraj, S. \& Iniyan, S. A review of energy models. Renew. Sustain. Energy Rev. 10, 281-311 (2006).

${ }^{3}$ Connolly, D., Lund, H., Mathiesen, B. V. \& Leahy, M. A review of computer tools for analysing the integration of renewable energy into various energy systems. Appl. Energy 87, 1059-1082 (2010).

${ }^{4}$ Crawley, D. B., Hand, J. W., Kummert, M. \& Griffith, B. T. Contrasting the capabilities of building energy performance simulation programs. Build. Environ. 43, 661-673 (2008).

${ }^{5}$ Huber, J. \& Nytsch-Geusen, C. Development of Modeling and Simulation Strategies for Large-Scale Urban Districts. Proc. Build. Simul. 14-16 (2011).

${ }^{6}$ Thomas, D., Miller, C., Kämpf, J. \& Schlueter, A multiscale co-simulation of EnergyPlus and CitySim models derived form a building information model. 469-476 (2012). 
With regard to this literature, this report presents the survey made in the scope of the subtask $B$. This survey focuses on the description of the tools mastered by the task members.

\subsubsection{Tools survey}

It was decided to submit a questionnaire for the tool survey. This survey was sent to task members who were responsible to reply to the questions and propose slight improvements. In the survey, the following points were addressed:

- Tool name

- Developer

- Small description (what does the tool simulate/evaluate)

- Input (description of the input type/file)

- Output (description of the output)

- Space resolution

- Time resolution

- Demand side (does it simulate the demand side)

- Supply side (does it simulate the supply side)

- Information exchange (inter operability /exchange with other software possible?)

- Is the output of the tool sufficient for the dimensioning

- What kind of meteo data it requires

- If it simulates the supply side what are the information needed on the supply side

- If it simulates the demand side what are the information needed on the demand side

- Does it allow economic analysis

- Type of license (Open source | Commercial | Academic)

- Application (Design | Analysis | Simulation | Evaluation )

The main objectives of this survey are the following:

- Description of available simulation and design tools integrating solar thermal modelling

- Space and time resolution of each tool

- Integration of variability and types of energy resources

- Existing and potential chain tools

After the surveys were returned by the task members, the data were used to generate tables and graphs reported as an annex of this document. This graphical representation provides a quick and concise overview of each tool and allows an efficient representation of potential tool chain. 
In this survey, 12 tools were investigated (with respective developers):

- PlanETer

- MEU

- CitySim

- B-Sol

- Smart Heat Design

- INVERT/EE-Lab

- Trnsys 17.1

- SIMPLEX

- EnergyPLAN

- EnergyPRo

- REMOD-D

- KomMod

- GenOpt 3.1.0

- $\quad$ TRNOPT 2.1.54
CREM

CREM

LESO-EPFL

HES-SO

CREM - LESO-EPFL - HES-SO

TU Vienna, Energy Economics Group

University of Wisconsin, TESS, Transsolar

Pink GmbH, Österreich

Aalborg University, Danemark

Aalborg University, Danemark

Fraunhofer ISE

Fraunhofer ISE

Lawrence Berkely National Laboratory

TRNOPT: University of Wisconsin, TESS

The description of many other energy system analysis models can be freely consulted online?.

\subsection{Assessment of the needs of urban actors 8}

\subsubsection{Goal}

The intention of the present assessment (activity B1-A) is to identify to which question(s)/expectations the developed methodology (B1-B) should answer - and consequently which of the tools (B2-A) would be the most adequate to address the identified needs.

To do so, first the urban actors will be identified (municipalities, planners...) and their needs will be assessed, respectively.

\subsubsection{Approach}

In order to structure the collection of information, a matrix has been created differentiating the type of actors and the scale of concern. The urban actors are sorted by groups of interest as follows:

- Local and regulatory authorities

o Municipality

o Energy governance/policies

- Utilities

o Thermal energy providers

o Power energy providers

${ }^{7}$ http://www.energyplan.eu/othertools/

${ }^{8}$ Assessment of the needs of urban actors - Author: G. Ruiz, CREM Martigny, July 2015 
o Water / wastewater companies

- Private companies

o Engineering offices

- Urban planners

o Equipment suppliers/ installers

- Academic

o Universities

o Research groups

- Citizens

o Household's owners

o Household's tenant

- Customers

- Communication / Media

Each of these actors can interact at different territorial boundaries or sphere of influence. These scales of concern are categorised as follows (bottom-up wise):

- Apartment

- Building

- Cluster/District

- City

- Region

- Country

This matrix questionnaire has been then shared to the expert's team asking them to fill it out with their experience with regard to the needs for integrating solar thermal in urban context. Furthermore, each input to this questionnaire starts with a "context" followed by a "need". An example is given in the figure here below.

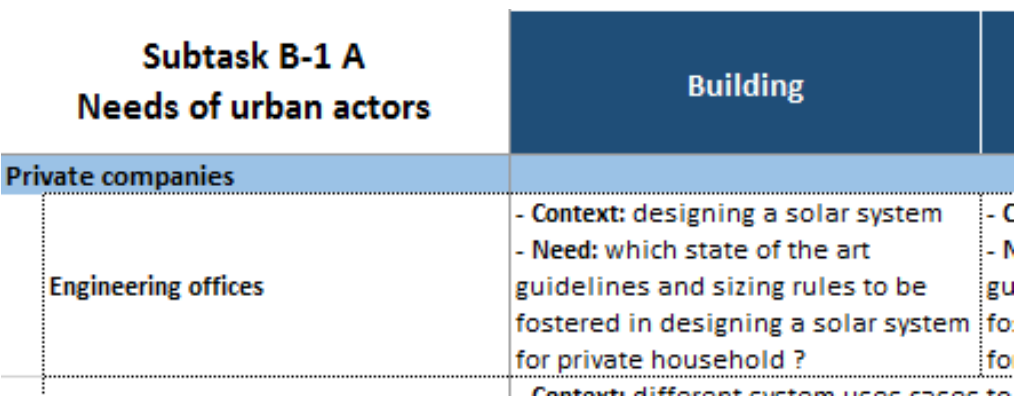

Figure 1 : Example of an urban actor's need captured from the Task 52 Team

\subsubsection{Results analysis}

A synthesis of the results is here proposed, sorted by actor groups. Furthermore, it is here proposed to summarize the outcomes by topics of concern rather than keeping a territorial scale as reference (although these details are available in the table). 


\subsubsection{Local and regulatory authorities}

Technical: Guidance for determining the solar potential and appropriate locations where to install a solar system.

Guidance for determining the best solar concepts (centralized or not, penetration rate ...) to be applied and under which technical, financial, urban pattern and architectural conditions.

Economic: Determine which technical concepts / systems size and locations are economically viable, or, under which conditions (legislation, market, subsidies ...) these become profitable.

Legislation: Clear directions / policies fostering an adequate use of solar heat systems, in a coherent way through the different territorial scales and in consideration to the other energy resources (gas, wood ...).

Politics: Define to which extent the solar thermal will contribute attain the energy objectives.

Create the required framework (economy, legislation...) to facilitate the implementation of solar thermal energy.

\subsubsection{Utilities}

Technical: Need for tools determining the best solar concepts (centralized or not, penetration rate ...) to be applied and under which technical, financial, urban pattern and architectural conditions.

Economic: Help defining profitable business models supporting the implementation of solar heat systems according to the urban characteristics (new or old quarter...).

Create new business around the model of (solar-) heat as a service, allowing producing solar heat even if not own consumed.

\subsubsection{Private companies}

Technical: $\quad$ Need for tools \& guidelines designing the best solar concepts (centralized or not, sizing, solar fraction ...) to be applied and under which technical, financial, urban pattern and architectural conditions.

Define which technical concept will contribute best to the meet the political objectives or one's client objective.

Economic: Compare profitability of different systems integrating solar energy (PV+Heat pump VS. Solar thermal; contribution of solar thermal energy when coupled to a district heating network ...)

Legislation: Define to which extent should architectural constraints and urban planning policies be adapted in order to facilitate the integration of solar thermal systems.

Politics: $\quad$ Awareness of the political community should be raised towards solar lobbying, given the appropriate and clear scientific guidelines available. 


\subsubsection{Academic}

Technical: Development of tools \& guidelines defining the best solar concepts (centralized or not, sizing, solar fraction ...) to be applied and under which technical, financial, urban pattern and architectural conditions

Knowledge sharing about solar solutions with actors concerned by concrete applications (at all levels). Need to integrate energy and sustainable developments aspects in urban/architectural education programs.

Economic: Development of models showing adequacy between technical solutions and economy benefits.

\subsubsection{Citizens}

Technical: Guidance for determining the solar potential at one's level and the technical concept to be promoted given financial and architectural conditions.

Economic: Guidance on the financial benefits for solar systems with regard to the recommended technical concept and pre-requisite conditions.

Politics: $\quad$ Create the required framework (economy, legislation...) to facilitate the implementation of solar thermal energy (given that solar is not always economically/spatially feasible on household level).

\subsubsection{Customers}

Technical: Guidance on the solar technology (solar thermal vs. PV) and solar integration concepts to be promoted, given its lifetime and profitability.

Propose simplified and robust systems facilitating its installation and minimizing the operating costs.

Economic: Propose heat prices, including or not solar energy.

Legislation: Offer the possibility to buy solar heat as service, even if no own system is feasible.

\subsubsection{Communication / Media}

Technical: $\quad$ Contribute to find opportunities for academic institutions to develop and implement innovative solutions by facilitating collaborations with different stakeholders.

Economic: Create ethical \& economic value around lodging (apartment, houses, hotels ...) that are using renewable energy like solar.

Politics: $\quad$ Propose dedicated information campaigns supported by the medias to foster the implementation of the solar integration. 


\subsubsection{Analysis}

Two main streams can be derived from this exercise: a scientific/technical aspect and influencing factors.

\subsubsection{Scientific/technical aspects}

Independently from the actor's type, almost all topics related to a technical / scientific aspect are concerned by the key question: "Which solar concept should be promoted, depending on the application scale?"

There is an obvious need to provide concept design guidelines at each scale. And these should furthermore be justified based on consideration like: technical implementation complexity, coherence with the urban plan, architectural constraints, economic benefit, energy savings and climate impact.

However, these considerations can be influenced by mean of less objective arguments than the scientific approach; the latter enabling to justify with energy and climate indicators the use of a system rather than another. These influencing arguments are discussed hereafter.

\subsubsection{Influencing factors}

It appears also clear from this survey that any scientifically sound guidance won't be effective without addressing major influencing factors. These factors have the capability to make a technology happen or not, in a given economy and social context.

To summarize, the main ones are:

- Politics: from which it is possible to obtain incentive and support, at all scales. But political support needs to rely on facts, coming back to drawing consistent scientific guidelines.

- Legislation: which can be changed if not adequate, given the required political support and awareness of the different stakeholders (citizens, equipment suppliers, academic community ...)

- Economic the cost of equipment can be influenced depending on the technology to be promoted and the market interest. O\&M costs can also become more or less attractive according to the evolution of conventional energy prices. Energy prices are again subject to the influence of political will that can counter-balance to some extent the macro economy levers.

\subsubsection{Identification of needs}

How should the research efforts towards the integration of solar heat be driven? One approach is to firstly define from a scientific point of view which systems to promote, under certain conditions, and then to think about the adequate economical, legislation and political levers that should be activated to make it happen. An alternative approach is to start from the actual existing frameworks and try to fit into it the most adequate solutions in terms of energy-climate-cost considerations.

One thing may be sure, the energy transition won't happen without adapting somehow the actual frameworks, on a political, legislative or economical level. And from the needs of urban actors, we identified that expectations towards all these topics prime on technical questions. A way to meet these identified needs is the development of the methodology described in the next chapter. 


\section{Development of a methodology to meet the needs of urban actors}

Since the addition of a solar thermal system in a district heating usually increases the cost of energy, it is necessary to highlight its many advantages. The final solution might not necessarily be the most economically profitable, but will contribute to the increase of renewable energy use.

In order to guide stakeholders in the elaboration of their energy concept, a methodological approach was developed. The graphical representation of the process is represented on the Figure 1 with the main following steps:

1. Project owner is either obliged or interested to elaborate an energy concept with a solar or renewable fraction in the energy mix. In order to pre-determine a solar concept, the initial constraints have to be determined. These constraints vary a lot from a project to another depending on, for instance, of the country legislation, the type of needs or the owner's financial capacity. A quite exhaustive list of indicators is shown in this report to include all possible constraints. These indicators are classified in three groups related to the framework, the boundary conditions and the energy system design.

2. Based on the initial constraints of the concept, a decision path was elaborated to guide the stakeholder in the pre-selection of an energy system. The decision path links the initial constraints, the available area for solar panel and main energy system classification developed in the subtask $C$.

3. Using the output of the decision path, an Excel-tool was elaborated to calculate solar indicators. Based on heated floor area and available space for solar panels, some relevant indicators can be calculated at early stage of the project. The tool can provide valuable estimation of the solar fraction, cost evaluation of the solar system or gains in the $\mathrm{CO}_{2}$ emissions.

4. During this process, new solutions more efficient or more specific to the situation can be highlighted. The initial energy concept can be refined and a new run for the determination of the solar indicators can be achieved.

The following section will develop these steps and present the tools and tables developed during this task. 


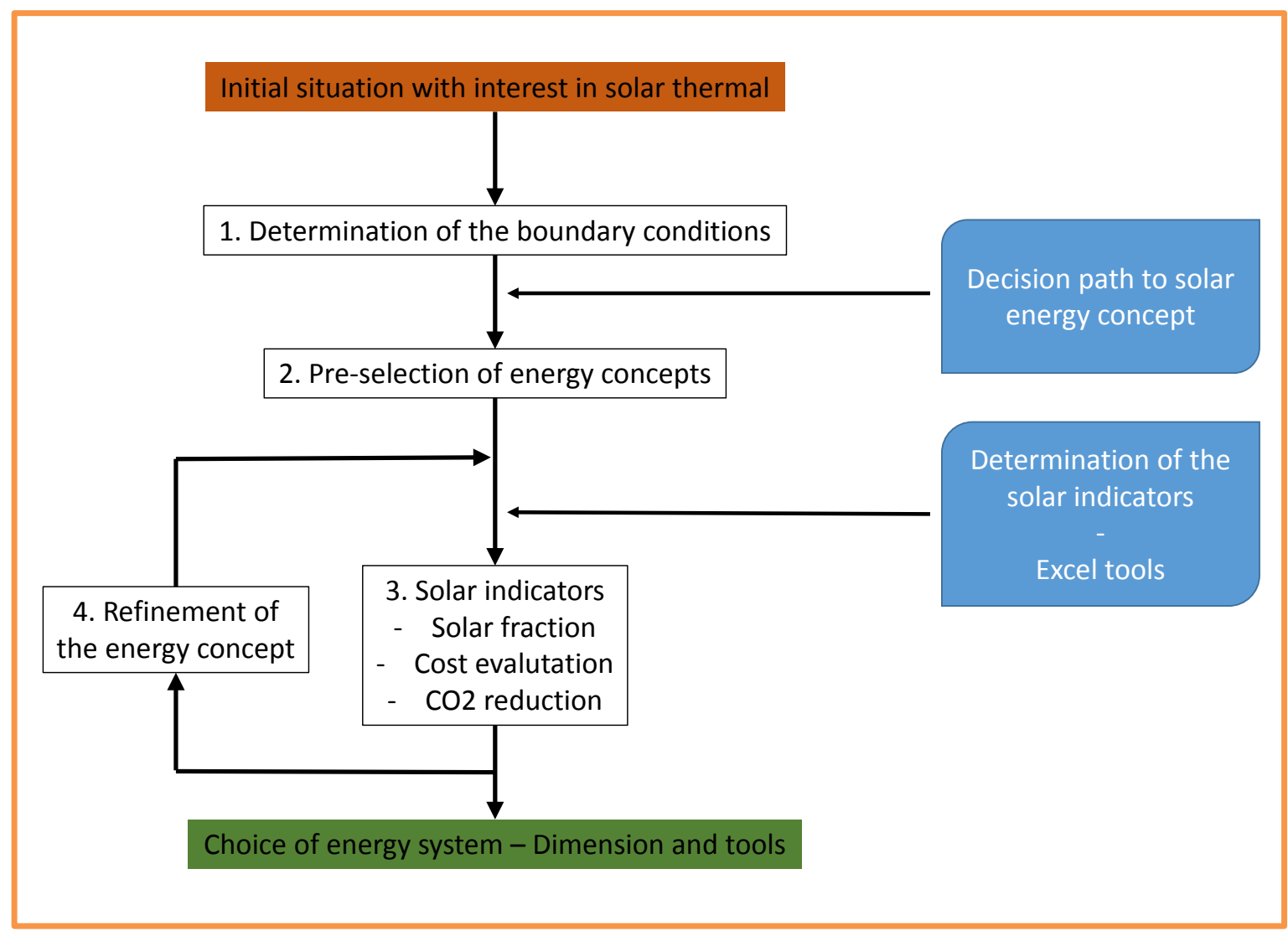

Figure 2 : Methodological approach: from boundary conditions to indicator energy system comparison. 


\subsection{Indicators and boundary conditions}

In order to make assumptions on the more adapted energy system it is of first importance to have an overview of the parameters that constraint the system. In our methodology, these parameters, called indicators, are organized in three different categories. The relevancy of each of those indicators can differ from a project to another. The table gives quite an exhaustive amount of parameters that can influence latter decision. It is therefore important to go through every categories.

The first category proposed in the table includes framework indicators. These indicators outlines the societal structures relevant to the energy system. While this first list contains not quantitative parameters, they are of first importance. The boundary indicators category provides indications of solar thermal applicability within a specific area in relation to the existing context. The last category includes design indicators of solar thermal applicability in a specific case. All indicators provided in the table are compiled and described in the following table.

\begin{tabular}{|c|c|c|}
\hline Level & Indicator & Explanation for inclusion \\
\hline \multirow{7}{*}{ 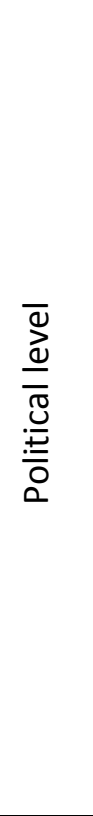 } & Framework indicators (structural) & $\begin{array}{l}\text { Indications of solar thermal applicability within } \\
\text { specific administrative borders e.g. country, } \\
\text { region or municipality }\end{array}$ \\
\hline & Subsidies (direct or indirect) & $\begin{array}{l}\text { Can support a positive business case for solar thermal } \\
\text { solutions }\end{array}$ \\
\hline & Legislation (promoting solar thermal) & $\begin{array}{l}\text { Can promote relevance/necessity of choosing solar } \\
\text { thermal solutions }\end{array}$ \\
\hline & Credit capability (financing options) & $\begin{array}{l}\text { Can minimize economic risk for investors to choose } \\
\text { solar thermal solutions }\end{array}$ \\
\hline & $\begin{array}{l}\text { Access to knowledge (experiences from } \\
\text { comparable areas/professionals) }\end{array}$ & $\begin{array}{l}\text { Can provide instant attention to critical conditions for } \\
\text { implementing solar thermal solutions }\end{array}$ \\
\hline & Project owner (nature of project owner) & $\begin{array}{l}\text { Can change the constraints and obligation on the } \\
\text { project }\end{array}$ \\
\hline & National or international commitment & $\begin{array}{l}\text { Can promote some type of project or disadvantage } \\
\text { others as a function of the national or international } \\
\text { targets }\end{array}$ \\
\hline \multirow{6}{*}{ 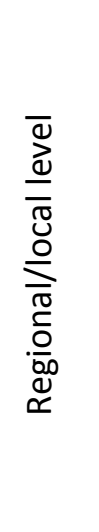 } & Boundary indicators (contextual) & $\begin{array}{l}\text { Indications of solar thermal applicability within } \\
\text { specific area in relation to existing context }\end{array}$ \\
\hline & Area population & Suitable scale (based on experience) \\
\hline & Heat density & $\begin{array}{l}\text { Critical mass, making sure there is a demand for the } \\
\text { (solar thermal) heat production }\end{array}$ \\
\hline & Heated building floor area & $\begin{array}{l}\text { Critical mass, making sure there is a demand for the } \\
\text { (solar thermal) heat production }\end{array}$ \\
\hline & Assignment & $\begin{array}{l}\text { Contribute to the calculation of the needs on the } \\
\text { demand size }\end{array}$ \\
\hline & Current heat price (savings per MWh) & Benchmarking cost-competitiveness of solar thermal \\
\hline
\end{tabular}




\begin{tabular}{|c|c|c|}
\hline & Existing dominant heat supply & Suitable technology (based on experience) \\
\hline & Irradiance density & Estimation of solar thermal production \\
\hline & Spatial availability & Size of suitable area available \\
\hline & Spatial value & Cost allocation for land acquisition \\
\hline & $\begin{array}{l}\text { Distance to connect supply and demand (from } \\
\text { ST plant to DH net) }\end{array}$ & Cost allocation for transmission pipes \\
\hline \multirow{12}{*}{ 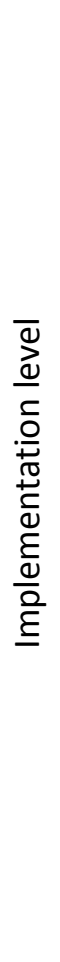 } & Design indicators (specific) & $\begin{array}{l}\text { Indications of solar thermal applicability in a } \\
\text { specific case }\end{array}$ \\
\hline & $\begin{array}{l}\text { Heat consumption per time step (e.g. monthly } \\
\text { or winter period \& summer period) }\end{array}$ & $\begin{array}{l}\text { Analysing heat demand in relation to fluctuating heat } \\
\text { production }\end{array}$ \\
\hline & Supply temperature levels (demand side) & Dimensioning technical solution to heat demand \\
\hline & Size of collector area & Dimensioning heat production to heat demand \\
\hline & Solar collector types & Optimization of energy production \\
\hline & Surface slope and orientation & Optimization of energy production \\
\hline & Cost of solar collectors & Calculating business case (feasibility) \\
\hline & $\begin{array}{l}\text { Solar fraction targeted for domestic hot water } \\
\text { and space heating }\end{array}$ & $\begin{array}{l}\text { Contribute to the calculation of parameters on the } \\
\text { demand size }\end{array}$ \\
\hline & Cost of pipe laying & Calculating business case (feasibility) \\
\hline & $\begin{array}{l}\text { Space for storage (possibility of constructing } \\
\text { heat storage) }\end{array}$ & $\begin{array}{l}\text { Dimensioning storage capacity taking the heat } \\
\text { demand into account }\end{array}$ \\
\hline & Storage types & $\begin{array}{l}\text { Optimization of energy production/heat losses and } \\
\text { feasibility }\end{array}$ \\
\hline & Cost of storage & Calculating business case (feasibility) \\
\hline
\end{tabular}




\subsection{Decision path - from boundary conditions to the solar energy systems}

This section describes the decision path elaborated in the frame of the task. The aim of this path is to provide an initial view of the energy concept. The structure of the path described in this report is presented in the annexes. This path works as a cross-linked decision tree.

The main elements of this path are the following:

- Boundary conditions

- Questions allowing to progress in the tree

- Classification according to a given energy system

These elements are described in flowing sections.

\subsubsection{Boundary conditions}

The boundary conditions can be determined with the indicators listed in the previous section. The basic idea is to provide a qualitative initial assessment of the main parameters of the project. The following indicators can be highlighted:

- Allocation and purpose of the heated surface. This question is linked to a central problematic of the temperature of the district heating.

- Availability of local resources

- Owner objectives in term of envelop performance, renewable fraction, or quality certification.

- Legal constrains in term of envelop performance, renewable fraction for electric or heat consumption or architectural constraints.

- New or existing district heating system

\subsubsection{Questions allowing to progress in the tree}

In order to progress in the decision tree, questions have to be answered. The following questions are addressed:

- Is there an existing district heating next to the area of the project?

- At a first glance, is the heat density of the network reasonably high?

- What is the temperature and the power available in the existing district heating?

- Are there some subsidies available for connecting to or creating a district heating?

- Does the connection to a district heating reach all the legislative requirements? For example in term of renewable fraction of energy?

- Is a seasonal storage possible?

- What is the available space for solar energy systems?

These questions can lead to various options in the energy concept. The solutions are multiple with or without solar, connected or not connected to district heating network. An interesting output of this decision path is to offer a link between these options and a classification of typical solar energy systems. These classifications is described in the next section. 


\subsubsection{Classification according to given energy system}

The decision path can make a link between initial constraints of the project and energy system proposals classified in five different types. These types are enumerated hereafter 9 :

- $\quad$ 1. Solar domestic hot water

- 2. Solar-combi systems in single family homes

- 3. Solar-combi systems in multi-family homes

- 4. Solar block heating

- 5. Solar district heating
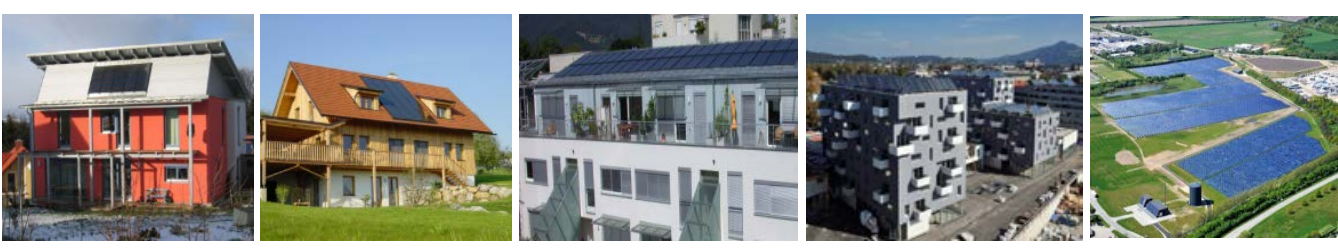

Figure 3: Typical examples of various solar thermal systems. From left to right, Solar domestic hot water, Solar-combi systems in single family homes, Solar-combi systems in multi-family homes, Solar block heating, Solar district heating.

The identification of a potential solar thermal system is a crucial step in the determination of solar indicators. The comparison of the calculated values, based on boundary conditions and potential energy system can lead to essential decision in the project.

${ }^{9}$ This classification is derived form the report "Classification and benchmarking of solar thermal systems in urban environments" of the subtask $C$ 


\subsection{Evaluation of solar indicators}

In order to estimate quantitatively the solar indicators, an Excel-tool was conceived. From basic data of the project, the tool can quantify the solar fraction, the energy cost or the $\mathrm{CO}_{2}$ emission variation. The following sections will described the tool:

- $\quad$ Requested inputs

- Outputs

- $\quad$ Assumptions

\subsubsection{Input}

To run this tool, the following basic information are needed:

- Country. The countries taken into account are Austria, Germany, France, Sweden and Switzerland. One of these countries has to be preselected.

- Heated floor area $\left[\mathrm{m}^{2}\right]$. In order to estimate the consumption of the building, the heated floor surface has to be filled in. This value is defined as the complete heated floor area including the wall surface and the insulation of the building. Three kinds of consumer profiles can be distinguished:

o Single family house

o Multi Family house

o Apartment Block

- Construction period. For each consumer profile, the construction period of the building has to be specified. The available periods cover the year 1900 to 2010 with a time step of 10 years.

- Refurbishment - Space heating gain [\%]. If the building was refurbished since its construction, this parameter allows the user to apply a correction coefficient to the space heating value. This coefficient can be adjusted if only a part of the real estate was refurbished. The entered value can vary between $0 \%$ (no refurbishment) to $100 \%$ (no need any more for space heating). The energy allocated to domestic hot water is not affected by this parameter.

- Collector total surface $\left[\mathrm{m}^{2}\right]$. The surface (gross area) that can be allocated for solar energy installations is indicated. This parameter is obviously linked to the solar fraction indicator.

- Size index - 1 to 5. The size index is a crucial parameter as the quantification of solar indicators is strongly dependent form the size of the installation. The determination of the class targeted in the project can be determined by using the decision path described in the section 3 . The chosen index corresponds to the class described in the Figure 3 . In this figure, an indication of the size of the solar field is shown.

\begin{tabular}{|l|r|r|}
\hline $\begin{array}{l}\text { Size index and classification of solar thermal energy } \\
\text { system }\end{array}$ & \multicolumn{2}{|c|}{$\begin{array}{c}\text { Estimation of the size of the } \\
\text { solar field [m2] }\end{array}$} \\
\cline { 2 - 3 } & Minimum & Maximum \\
\hline 1. Solar domestic hot water-DHW-SFH & 0 & 10 \\
\hline 2. Solar-combi systems in single family homes - CS-SFH & 10 & 30 \\
\hline 3. Solar-combi systems in multi-family homes - CS-MFH & 30 & 300 \\
\hline 4. Solar block heating - SBH & 300 & 5 '000 \\
\hline 5. Solar district heating - SHD & 5 '000 & 200 '000 \\
\hline
\end{tabular}

Figure 4: Estimation of the size of the solar field as a function of the size index and classification. 
- Additional production source. This parameter is linked to the saved emission of $\mathrm{CO}_{2}$. As district heating network depends most of the time form more than one energy source, the additional energy vector is requested for the $\mathrm{CO}_{2}$-tons emission calculation.

- Renewable fraction of the heat network [\%]. For the saved $\mathrm{CO}_{2}$ emission as well, a part of the energy delivered by a heating network could be already renewable (waste burning, wood, energy recovery,...). This part won't be taken into account in the solar heat saved $\mathrm{CO}_{2}$ emission.

\subsubsection{Output}

Using the inputs described in the preceding section, a quantification of solar indicators can be obtained. The outputs of the tool are the following:

- Max solar fraction. The maximum solar fraction quantifies the energy provided by solar energy radiation compared to total energy consumption needed for the space heating and domestic hot water. To target a solar fraction above $20 \%$, the question of the storage has to be carefully treated. In such situation, the diurnal and seasonal storage space needs are indicated.

- Diurnal storage. In a situation where a diurnal storage is targeted, this parameter provides an estimation of the volume requested for the tank.

- Seasonal storage. In a situation where a seasonal storage is targeted (most of the time to target a high solar fraction), this parameter provides an estimation of the volume requested for the tank.

- Heat density. A crucial indicator to determine if a district heating is economically viable is the heat density of the network. This indicator is function of the energy delivered by the network and the length of the network itself. However, the economic viability of a heat varies a lot from a country to another. The output given in this tool is thus the length of the network to reach the mean heat density of the districts heating of a given country.

- Specific solar thermal system cost $\left[€ / \mathrm{m}^{2}\right]$. This parameter refers to the cost to end-user for ready-installed (turnkey) systems (absorbers and storage) excluding taxes or subsidies.

- Energy cost [€/year] and [€/kWh]. This output represents the levelized cost for solar energy system in central Europe countries. Costs are given for diurnal or seasonal storages.

- Saved $\mathrm{CO}_{2}$ emission [ton- $\mathrm{CO}_{2}$ ]. By using solar heat in an energy system instead of non-renewable resources, part of the $\mathrm{CO}_{2}$ emissions can be avoided. This output quantifies how many tons of $\mathrm{CO}_{2}$ can be avoided.

\subsubsection{Assumptions}

In order to quantify the indicators given in the previous section, some assumptions were applied. This section describes the methodology applied for:

- Needs quantification

- Solar production quantification

- Dimension of the solar thermal system and estimation of the cost

- Avoided emission quantification 
- Quantification of the mean district length as a function of the nation heat density network distribution.

These points are described in the following subsections.

\subsubsection{Needs quantification}

The needs of the project are the addition of the needs for space heating and domestic hot water production. For domestic hot water, the Swiss norm SIA 380/1 values were applied. The following figure represents the values used for the calculation as a function of the type of consumers.

\begin{tabular}{|c|c|}
\hline Type & $\begin{array}{c}\text { Domestic hot } \\
\text { water }[\mathrm{kWh} / \mathrm{m} 2]\end{array}$ \\
\hline Single family house & 13.9 \\
\hline Multi Family house & 20.8 \\
\hline Apartment Block & 20.8 \\
\hline
\end{tabular}

Figure 5: Specific energy needed for domestic hot water production.

For the space heating, values were taken from literature. Specific values were extracted from the TABULA WebTool10 database. This database has been developed within the framework of the Intelligent Energy Europe projects TABULA and EPISCOPE. For Swiss consumption, alternative literature sources were used ${ }^{11}$ instead.

\subsubsection{Solar production quantification}

The solar production is calculated on a yearly basis by multiplying the available gross area by the solar yield. This parameter, taken from the benchmark of the STC ${ }^{12}$ as a function of the energy system classification, is corrected by the global solar irradiation values onto optimally inclined collector surface $\mathrm{G} 0$, incl $\left[\mathrm{kWh} /\left(\mathrm{m}^{2} . \mathrm{a}\right)\right]^{13}$.

\begin{tabular}{|l|r|}
\hline & G0,incl [kWh/(m2.a)] \\
\hline Austria - Wien & 1300 \\
\hline France - Paris & 1400 \\
\hline Germany - Berlin & 1300 \\
\hline Sweden - Gothenburg & 1330 \\
\hline Switzerland - Zurich & 1420 \\
\hline
\end{tabular}

Figure 6: global solar irradiation values for an optimally inclined collector surface

\footnotetext{
${ }^{10} \mathrm{http}: / /$ webtool.building-typology.eu/

${ }^{11}$ Groupe d'action combustibles Stratégie du groupe d'action objectifs sectoriels organisation

${ }^{12}$ Technology and Demonstrators - Technical Report Subtask C - Part C1, F. Mauthner and S. Herkel

${ }^{13} \mathrm{http}: / /$ re.jrc.ec.europa.eu/pvgis/cmaps/eur.htm\#CH 


\subsubsection{Dimension of the solar thermal system and estimation of the cost}

The values taken into account to dimension and quantify the cost are derived from the benchmark of the STC ${ }^{14}$. It is based on sets of best practice examples in operation from countries participating in IEA-SHC Task 52 (AT, DE, and DK). In sum, 46 systems were investigated.

The tool gives information to the user on the type of storage to apply, seasonal or diurnal. For small scale solar systems for domestic hot water or solar combi systems in single or multifamily homes, the seasonal storage is in most cases not interesting or profitable. In the tool, the values linked to seasonal storage are indicated when the two following parameters are checked:

- The global solar target for domestic hot water and space heating for the buildings exceeds $20 \%$

- The solar energy system corresponds to Solar block heating or solar district heating types

\subsubsection{Avoided emission quantification}

The avoided emissions are derived from the following equation

$$
\varepsilon=E_{\text {sol }}(1-\rho) * \epsilon
$$

Where

$\varepsilon-$ Avoided emissions $\left[\mathrm{CO}_{2}\right.$-tons/year $]$

$E_{\text {sol }}$ - Maximum solar energy production [KWh/year]

$\rho$ - Existing renewable fraction of the district heating [-]

$\in-$ Emission coefficient $\left[\mathrm{CO}_{2}\right.$-tons $\left./ \mathrm{kWh}\right]$

The emission coefficients are derived from the literature ${ }^{15}$ as a function of the energy vector.

\subsubsection{Quantification of the mean district length as a function of the nation heat density network distribution.}

To determine if a district heating is profitable or not, a criterion based on average district heating heat density of for a given country is developed in this study. The heat densities mean value of existing district heating in Austria, Germany, France, Sweden and Switzerland were found in literature ${ }^{16}$ (Figure 6). This parameter characterizes the total annual amount of energy delivered by the district heating divided by the total length of the network. As losses and the costs increase with this length, a district heating should maximize this parameter to optimize the profitability of the system.

By dividing the national mean heat density by the total energy needs, a pipe length can be determined. This value represents the national mean length of a district heating for a given annual amount of energy delivered. This value doesn't represent a threshold limit

\footnotetext{
${ }^{14}$ Technology and Demonstrators - Technical Report Subtask C - Part C1, F. Mauthner and S. Herkel

${ }^{15}$ Facteurs d'émission de $\mathrm{CO}_{2}$ selon l'inventaire des gaz à effet de serre de la Suisse, OFEN, 2016

${ }^{16}$ Euroheat \& Power; 2011 
for the economic viability of a project. But it provides a benchmark value for ongoing projects.

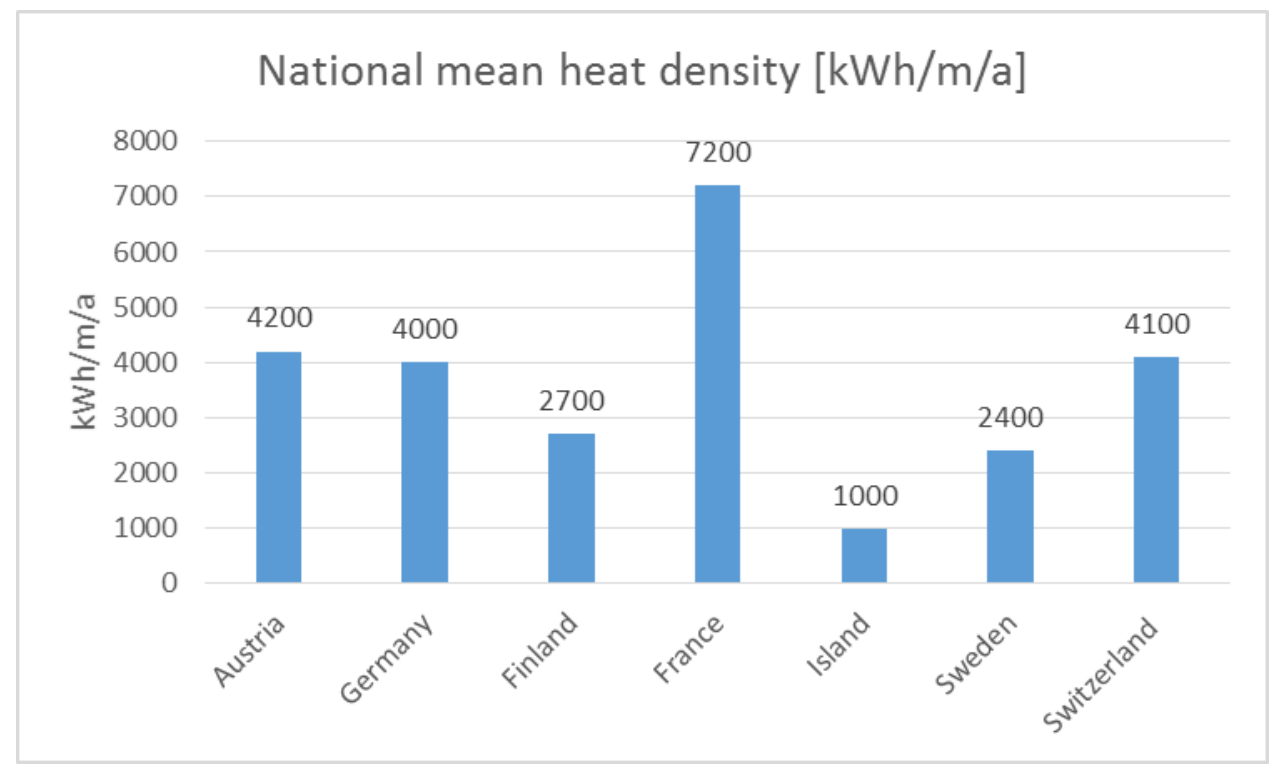

Figure 7 : Heat density mean values of district heating in Europa ${ }^{17}$.

\subsection{Evaluation of solar indicators}

The developed methodology with its decision path and excel calculation tool were challenged using the reported best practice example ${ }^{18}$. During an expert meeting, this decision path was tested with each participant responsible of a case study. The decision path could always lead to the same concept as the installed concept. This means its role to easily guide to a suitable energy system is achieved; it works effectively as a "go/no go" for concepts including the possibility of solar thermal. Even if quite basic, this decision path is pertinent, especially because it considers contextual and technical best practice aspects.

The use of the excel calculation tool gives good results even in terms of economic evaluation and solar fraction estimation (giving more credit to the quality of the benchmark realized in Subtasks $\mathrm{C}^{19}$ ). The following figures show the comparison of the values obtained from installed systems and the values obtained by applying the methodology and using the excel tool.

\footnotetext{
17 Euroheat \& Power; 2011

18 TECHNOLOGY AND DEMONSTRATORS - Technical Report Subtask B - Part B3, F. Mauthner, M. Joly and P. Bourdoukan, 2017
}

${ }^{19}$ TECHNOLOGY AND DEMONSTRATORS - Technical Report Subtask C - Part C1, F. Mauthner, S. Herkel, 2017 


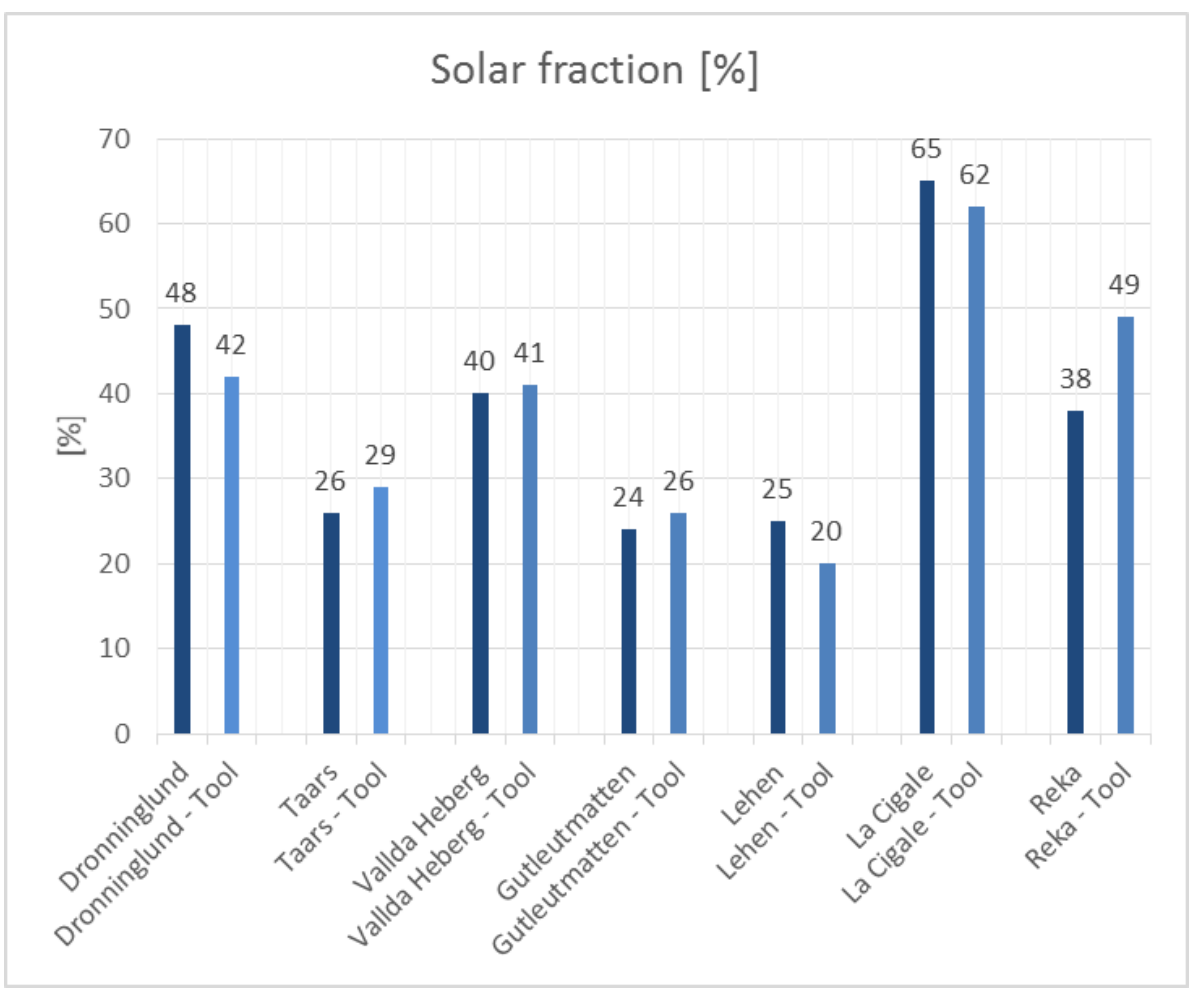

Figure 8 : Representation of measured and calculated solar fractions. Dark blue, the values obtained from installed systems. Light blue, the values obtained with the tool. 


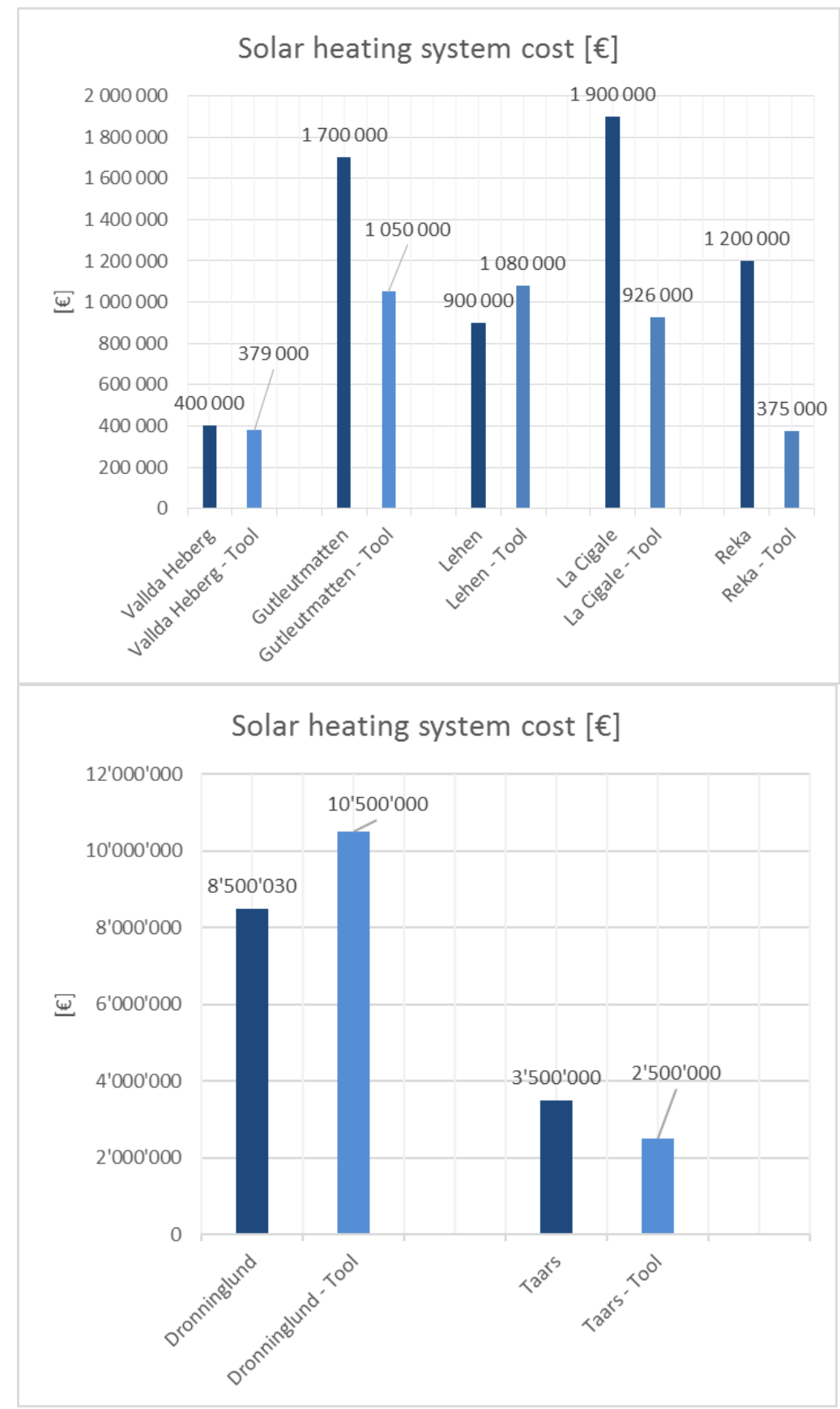

Figure 9 : Representation of measured and calculated solar heating system cost. Dark blue, the values obtained from installed systems. Light blue, the values obtained with the tool.

The values obtained with the tool are generally in good agreement with the measured values. Some of these reported cases benefitted from subsidies (for being pioneers in the retained solar assisted concept), thus twisting somehow the cost comparison. The results shown in the preceding figures are encouraging but don't bring a final proof of its accuracy. Nevertheless, these examples show that solar indicators and solar heating system cost can be roughly estimated by this method at a very early stage of a project. The strength of the method relies on the wide range of countries and solar energy system types that can be evaluated on the basis of only two surfaces estimations. 


\section{Conclusion}

In conclusion, this work allowed the development of a methodology that provides the stakeholders a simple and efficient decision support for early stage energy system design, helping them to progress in the development of the energy concept of their projects. Based on a survey of existing solar energy systems and buildings consumptions, it integrates a tool that is able to quantify some crucial indicators. The main input parameters are the heated floor area, the solar thermal area and the building typology. The main indicators provided are the solar fraction, the annual solar energy yield and the solar heating system cost. The strength of the method relies on the wide range of countries and solar energy system types that can be evaluated with only a few inputs.

This methodology answers the lack of pre-selection solutions identified at the beginning of the IEA Task 52. Its role is not to promote solar thermal at any cost but guide the user towards best suitable system for a given project. We are convinced that if stakeholders can easily evaluate, form an early stage, the benefits of solar thermal, they are far more likely to integrate it in their final projects. 


\section{Glossary}

\begin{tabular}{|c|c|c|c|}
\hline Term & Abbreviation & Definition & Source \\
\hline Best practice example & & $\begin{array}{l}\text { Collection of real examples that answer to a } \\
\text { given question as a function of defined } \\
\text { criteria }\end{array}$ & \\
\hline $\begin{array}{l}\text { Building Cooling Heating } \\
\text { and Power }\end{array}$ & $\mathrm{BCHP}$ & Application of trigeneration in buildings & \\
\hline Building typology & & $\begin{array}{l}\text { A building typology describes building types } \\
\text { with the same set of parameters. It includes } \\
\text { geographical distribution, age and other } \\
\text { important building features related to the } \\
\text { aims of the project }\end{array}$ & P.Schwer, R. Fischer \\
\hline Case studies & & $\begin{array}{l}\text { Case studies is a research method which } \\
\text { involves an in-depth, longitudinal } \\
\text { examination of a single instance or event: a } \\
\text { case. They provide a systematic way of } \\
\text { looking at events, collecting data, analysing } \\
\text { information, and reporting the results. }\end{array}$ & Wikipedia \\
\hline Chain tool & & $\begin{array}{l}\text { the tools forming a toolchain are executed } \\
\text { consecutively so the output of each tool } \\
\text { becomes the input for the next one }\end{array}$ & Wikipedia \\
\hline Cogeneration & & $\begin{array}{l}\text { Co-generation or Combined Heat and Power } \\
\text { (CHP) is the simultaneous generation of both } \\
\text { electricity } \\
\text { and heat from the same fuel, for useful } \\
\text { purposes. }\end{array}$ & $\begin{array}{l}\text { IEA - Cogeneration } \\
\text { and renewables - } \\
\text { Solutions for a low- } \\
\text { carbon future }\end{array}$ \\
\hline $\begin{array}{l}\text { Combined Heat and } \\
\text { Power District Heating }\end{array}$ & CHPDH & Cogeneration based district heating & \\
\hline Combined Heat Power & $\mathrm{CHP}$ & $\begin{array}{l}\text { Co-generation or Combined Heat and Power } \\
\text { (CHP) is the simultaneous generation of both } \\
\text { electricity } \\
\text { and heat from the same fuel, for useful } \\
\text { purposes. }\end{array}$ & $\begin{array}{l}\text { IEA - Cogeneration } \\
\text { and renewables - } \\
\text { Solutions for a low- } \\
\text { carbon future }\end{array}$ \\
\hline
\end{tabular}




\begin{tabular}{|c|c|c|c|}
\hline $\begin{array}{l}\text { Cumulated } \\
\text { Demand }\end{array}$ & CED & $\begin{array}{l}\text { The CED describes the consumption of fossil, } \\
\text { nuclear and renewable energy sources along } \\
\text { the life cycle of a good or a service. This } \\
\text { includes the direct uses as well as the indirect } \\
\text { (grey) consumption of energy due to the use } \\
\text { of materials (e.g. plastic or wood in } \\
\text { construction), consumables necessary in } \\
\text { manufacturing (e.g., solvents, gloves, } \\
\text { packaging) and raw materials. }\end{array}$ & $\begin{array}{l}\text { IEA - Methodology } \\
\text { Guidelines on Life } \\
\text { Cycle Assessment of } \\
\text { Photovoltaic } \\
\text { Electricity }\end{array}$ \\
\hline $\begin{array}{l}\text { Cumulated } \\
\text { Demand }\end{array}$ & CExD & $\begin{array}{l}\text { CExD expresses the gross exergy of all natural } \\
\text { resources, both renewable and non- } \\
\text { renewable, required to deliver a product }\end{array}$ & $\begin{array}{l}\text { Environmental } \\
\text { indicators - R. H. } \\
\text { Armon }\end{array}$ \\
\hline Distric heating and cooling & $\mathrm{DHC}$ & $\begin{array}{l}\text { Network able to deliver heating and cooling } \\
\text { vectors }\end{array}$ & MJ \\
\hline Heat network & & District heating & \\
\hline Energy balancies & & $\begin{array}{l}\text { The considered system is at equilibrium, the } \\
\text { energy entering in the equal to the energy } \\
\text { going out }\end{array}$ & mj \\
\hline Energy scenario & & $\begin{array}{l}\text { Energy scenarios provide a framework for } \\
\text { exploring future energy perspectives, } \\
\text { including various combinations of } \\
\text { technology options and their implications. }\end{array}$ & $\begin{array}{l}\text { Nebojsa } \\
\text { cenovi' c }\end{array}$ \\
\hline Energy supply system & & $\begin{array}{l}\text { Description of a process able to deliver } \\
\text { energy, from primary energy to useful energy }\end{array}$ & Robert N. Schock \\
\hline Energy system & & $\begin{array}{l}\text { Description of a process, from primary } \\
\text { energy to useful energy }\end{array}$ & Robert N. Schock \\
\hline $\begin{array}{l}\text { Geographic information } \\
\text { system }\end{array}$ & GIS & $\begin{array}{l}\text { is a system designed to capture, store, } \\
\text { manipulate, analyse, manage, and present all } \\
\text { types of spatial or geographical data. }\end{array}$ & Wikipedia \\
\hline Heat density & & $\begin{array}{l}\text { Heat consumed in an urban area as a } \\
\text { function of the surface }\end{array}$ & \\
\hline $\begin{array}{l}\text { Integration of solar } \\
\text { thermal system }\end{array}$ & & $\begin{array}{l}\text { The architectural integration quality can be } \\
\text { defined as the result of a controlled and } \\
\text { coherent integration of the solar collectors } \\
\text { simultaneously under all functional, } \\
\text { constructive, and formal (aesthetic) points of } \\
\text { view }\end{array}$ & Munari-Probst \\
\hline $\begin{array}{l}\text { International Energy } \\
\text { Agency }\end{array}$ & IEA & $\begin{array}{l}\text { The International Energy Agency is a } \\
\text { autonomous intergovernmental } \\
\text { organization established in the framework of } \\
\text { the Organisation for Economic Co-operation } \\
\text { and Development (OECD) }\end{array}$ & Wiki \\
\hline Methodology & & $\begin{array}{l}\text { A body of practices, procedures, and rules } \\
\text { used by those who work in a discipline }\end{array}$ & The free dicionary \\
\hline
\end{tabular}




\begin{tabular}{|c|c|c|c|}
\hline Renewable energy & & $\begin{array}{l}\text { Renewable energy is generally defined as } \\
\text { energy that comes from resources which are } \\
\text { naturally replenished on a human timescale, } \\
\text { such as sunlight, wind, rain, tides, waves, and } \\
\text { geothermal heat }\end{array}$ & IPSOS 2011 \\
\hline Simulation tool & & $\begin{array}{l}\text { Software able to simulate real phenomenon } \\
\text { with a mathematical model }\end{array}$ & \\
\hline $\begin{array}{l}\text { Solar Heating and Cooling } \\
\text { programme }\end{array}$ & $\mathrm{SHC}$ & $\begin{array}{l}\text { The Solar Heating and Cooling Programme } \\
\text { (SHC) was established in 1977, one of the } \\
\text { first programmes of the International Energy } \\
\text { Agency, to promote the use of all aspects of } \\
\text { solar thermal energy. The Programme's work } \\
\text { is unique in that it is accomplished through } \\
\text { the international collaborative effort of } \\
\text { experts from member countries and the } \\
\text { European Union. }\end{array}$ & IEA \\
\hline Solar potential & & $\begin{array}{l}\text { Amount of energy potentially provided by } \\
\text { the sun radiation }\end{array}$ & \\
\hline Solar thermal energy & STE & $\begin{array}{l}\text { Solar thermal energy (STE) is a form of energy } \\
\text { and a technology for harnessing solar energy } \\
\text { to generate thermal energy or electrical } \\
\text { energy for use in industry, and in the } \\
\text { residential and commercial sectors. }\end{array}$ & wiki \\
\hline Solar thermal system & & $\begin{array}{l}\text { System with a solar collector able to convert } \\
\text { radiative energy of the sun into heat }\end{array}$ & \\
\hline Heat pump & & $\begin{array}{l}\text { Device that provides heat energy from a } \\
\text { source of heat to a destination called a "heat } \\
\text { sink". }\end{array}$ & \\
\hline Urban area & & $\begin{array}{l}\text { An urban area is a location characterized by } \\
\text { high human population density and vast } \\
\text { human-built features in comparison to the } \\
\text { areas surrounding it. }\end{array}$ & \\
\hline Urban energy system & & $\begin{array}{l}\text { The combined processes of acquiring and } \\
\text { using energy to satisfy the energy service } \\
\text { demands of a given urban area }\end{array}$ & James Keirstead \\
\hline Time resolution & & $\begin{array}{l}\text { Precision of a measurement or a simulation } \\
\text { as a function of time }\end{array}$ & \\
\hline Space resolution & & $\begin{array}{l}\text { Precision of a measurement or a simulation } \\
\text { as a function of a distance or a surface }\end{array}$ & \\
\hline Electrical grid & & $\begin{array}{l}\text { Interconnected network for delivering } \\
\text { electricity from suppliers to consumers }\end{array}$ & wiki \\
\hline Gas grid & & Network of the gas distribution & \\
\hline
\end{tabular}




\begin{tabular}{|c|c|c|c|}
\hline Micro-grid or smart-grid & & $\begin{array}{l}\text { Small-scale power grid that can operate } \\
\text { independently or in conjunction with the } \\
\text { area's main electrical grid. }\end{array}$ & Whatls \\
\hline Co-simulation & & $\begin{array}{l}\text { Modelling and simulation of different } \\
\text { subsystems which form a coupled problem in } \\
\text { a distributed manner }\end{array}$ & Wiki \\
\hline $\begin{array}{l}\text { Combined cooling, heat } \\
\text { and power or } \\
\text { trigeneration }\end{array}$ & $\mathrm{CCHP}$ & $\begin{array}{l}\text { Process that refers to the simultaneous } \\
\text { generation of electricity and useful heating } \\
\text { and cooling from the combustion of a fuel or } \\
\text { a solar heat collector. }\end{array}$ & wiki \\
\hline Fuel & & $\begin{array}{l}\text { Refers to coal, biomass, natural gas, nuclear } \\
\text { material, the sun or the heat stored in the } \\
\text { earth. }\end{array}$ & $\begin{array}{l}\text { IEA - Cogeneration } \\
\text { and renewables - } \\
\text { Solutions for a low- } \\
\text { carbon future }\end{array}$ \\
\hline Exergy & & $\begin{array}{l}\text { Exergy is the concept that explicitly indicates } \\
\text { 'what is consumed' }\end{array}$ & $\begin{array}{l}\text { Introduction to the } \\
\text { Concept of Exergy - } \\
\text { Masanori Shukuya \& } \\
\text { Abdelaziz Hammache }\end{array}$ \\
\hline
\end{tabular}




\section{Annexes}

\subsection{Decision path}

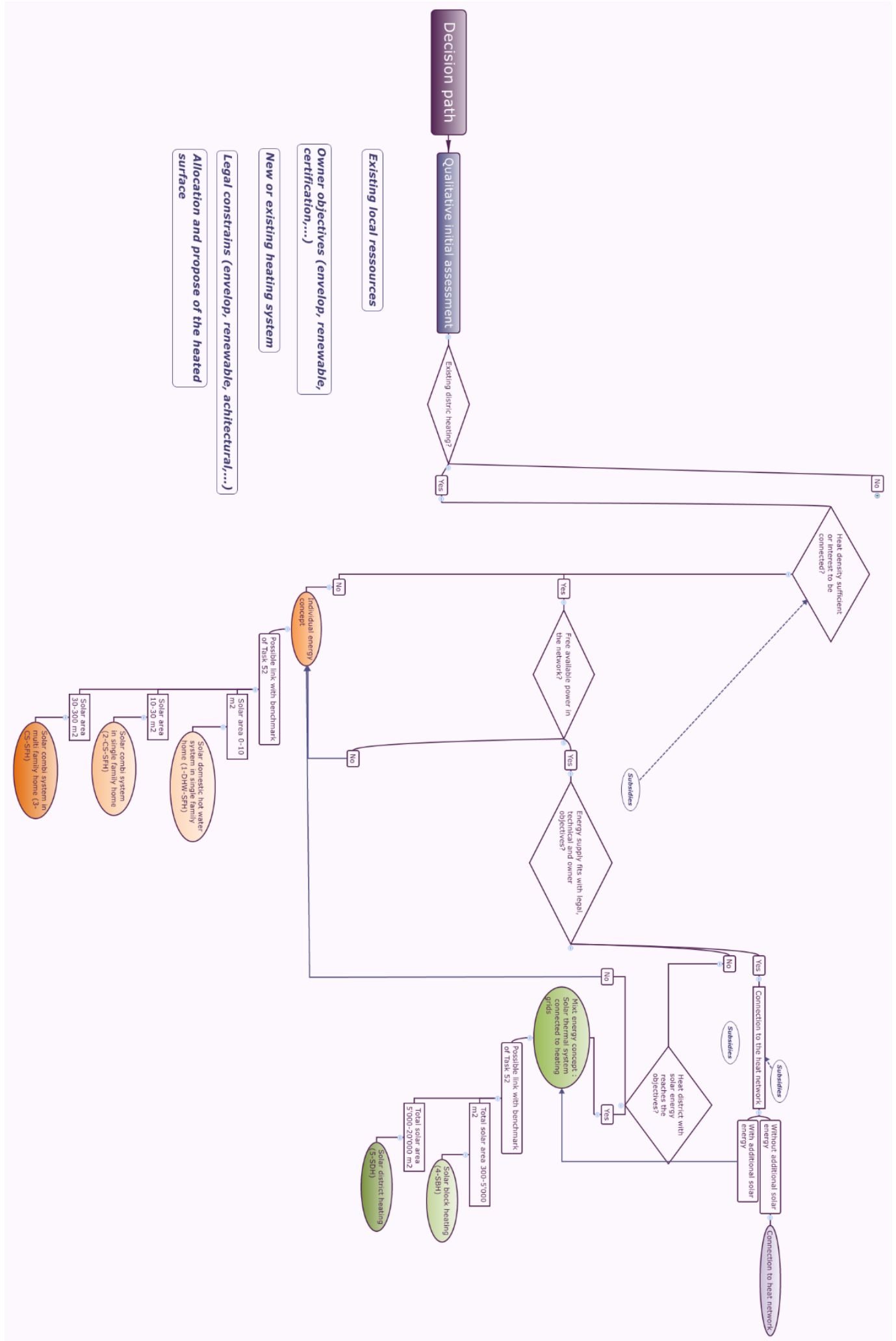

Figure 10 : Decision path representation. Part of the tree with existing district heating. 


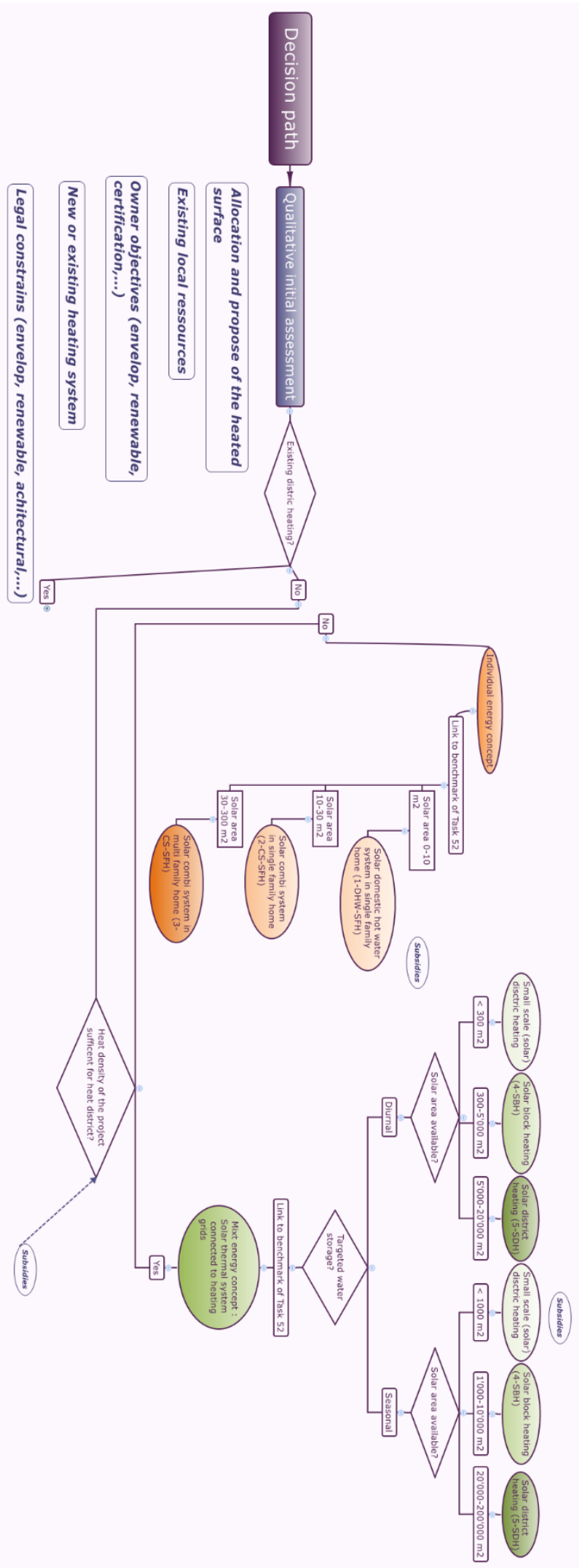

Figure 11 : Decision path representation. Part of the tree without existing district heating. 


\subsection{Tools description}

In the following subsections, each tool will be described by a short description, a schematic representation and some comments on strength and weakness. The graphics are composed of shapes disposed in a table. The table is separated in three lines representing three scales resolution. From top to bottom, the first, second and third lines are related respectively to building, district and country dimension. On it are disposed shapes linked with arrows.

The square, containing the name of the tool, is placed in the table as a function of its space resolution. The coloured parallelepiped shapes linked to the square indicate the input elements needed to run the tool. The grey ovoid shapes linked to the square indicate the output of the tool. The preceding principles are schematically described in the following figure.

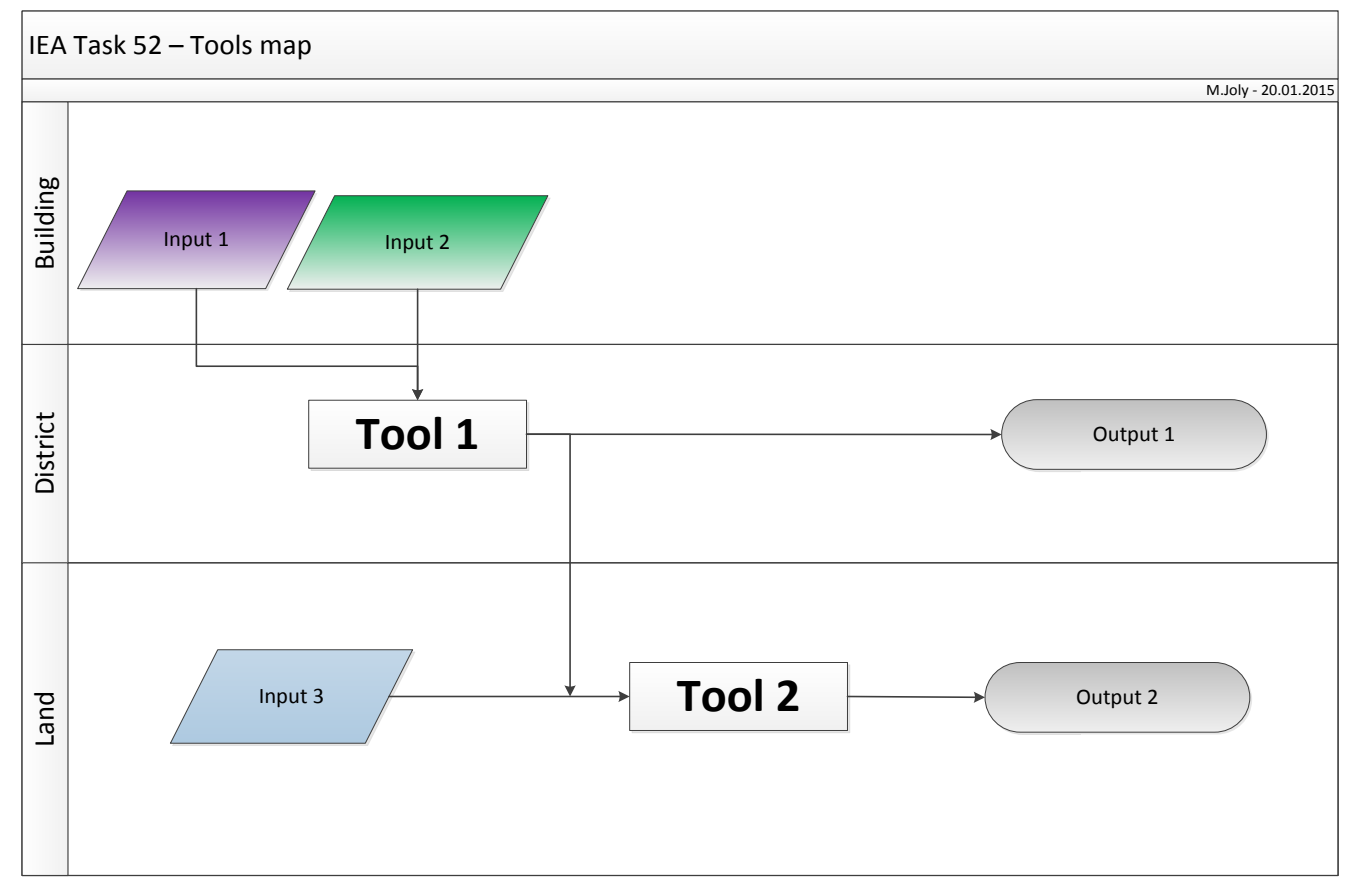

Tool name (developer)

This graphical representation of the flux allows us to:

- Understand the data flow in a wink

- Connect tools together in order to build complex chain tools

Moreover, the tools can be regrouped according to their function. The following classification groups were used:

- Tools for energy balancing

- Tools for thermal, electrical or hydraulic simulations

- Tools for optimization

- Others: GIS, tool frameworks, co-simulation platforms 


\subsubsection{Tools for energy balancing}

\subsubsection{EnergyPLAN}

Short description: EnergyPLAN simulates the operation of national energy systems on an hourly basis, including the electricity, heating, cooling, industry, and transport sectors. The model is used by many researchers, consultancies, and policymakers worldwide. This is possible due to the key focus on sharing the model during its development. For example, the model has a user-friendly interface, it is disseminated as a freeware, there is a variety of training available including our forum, and existing models are already available for many countries. The EnergyPLAN model has been used in hundreds of scientific publications and reports.

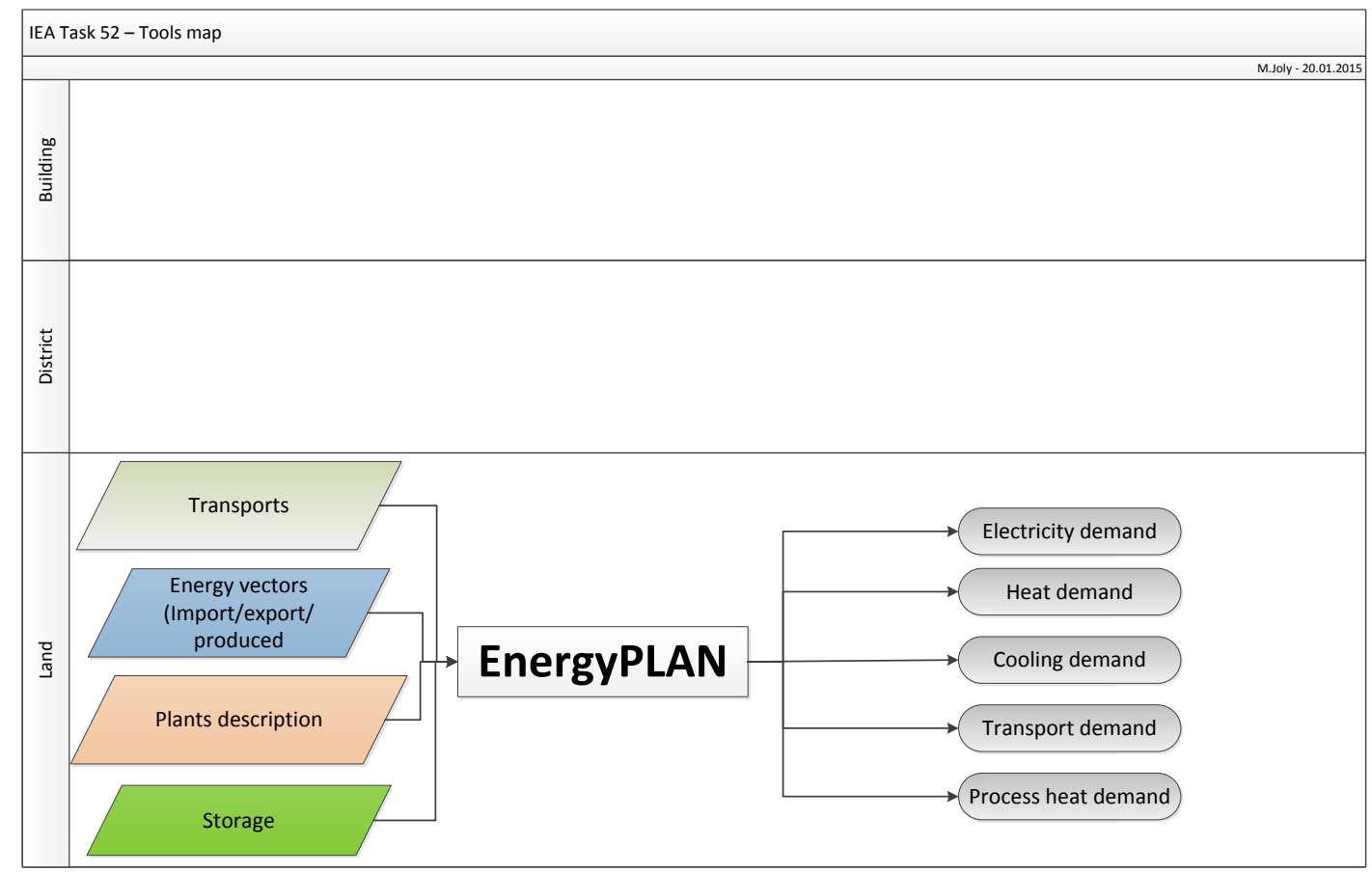

EnergyPLAN (Aalborg University, Danemark) 


\subsubsection{Energy PRO}

Short description: energyPRO is the most advanced and flexible modelling software for combined techno-economic optimisation and analysis of both co- and trigeneration projects. With energyPRO you can model and simulate all kinds of energy plants in existing as well as planned energy projects. energyPRO-functions include:

- Calculate the optimal operation of an energy plant

- Make detailed investment analyses

- Model industrial cogeneration

- Simulate energy plants participating on different electricity markets

- Analyse the interaction between separate energy plants

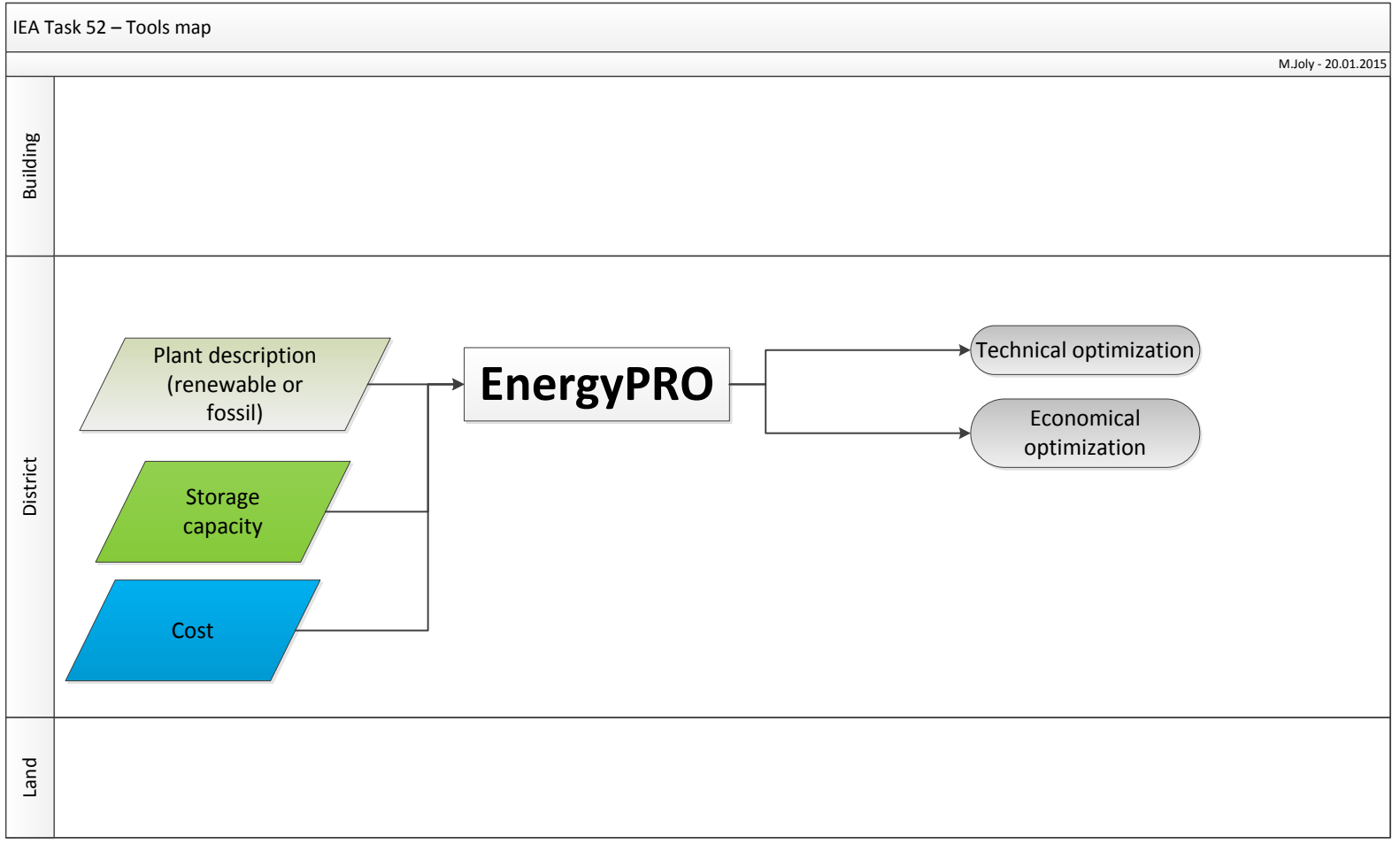

EnergyPRO (Aalborg University, Danemark) 


\subsubsection{INVERT/EE-Lab}

Short description: Calculation of energy demand in buildings (space heating and cooling, hot water, and lighting), simulation of investment decisions in

a) Renovation measures and thermal quality of new buildings,

b) In new technologies for heating and hot water preparation; simulation of the diffusion of cooling appliances as well as investments in PV systems

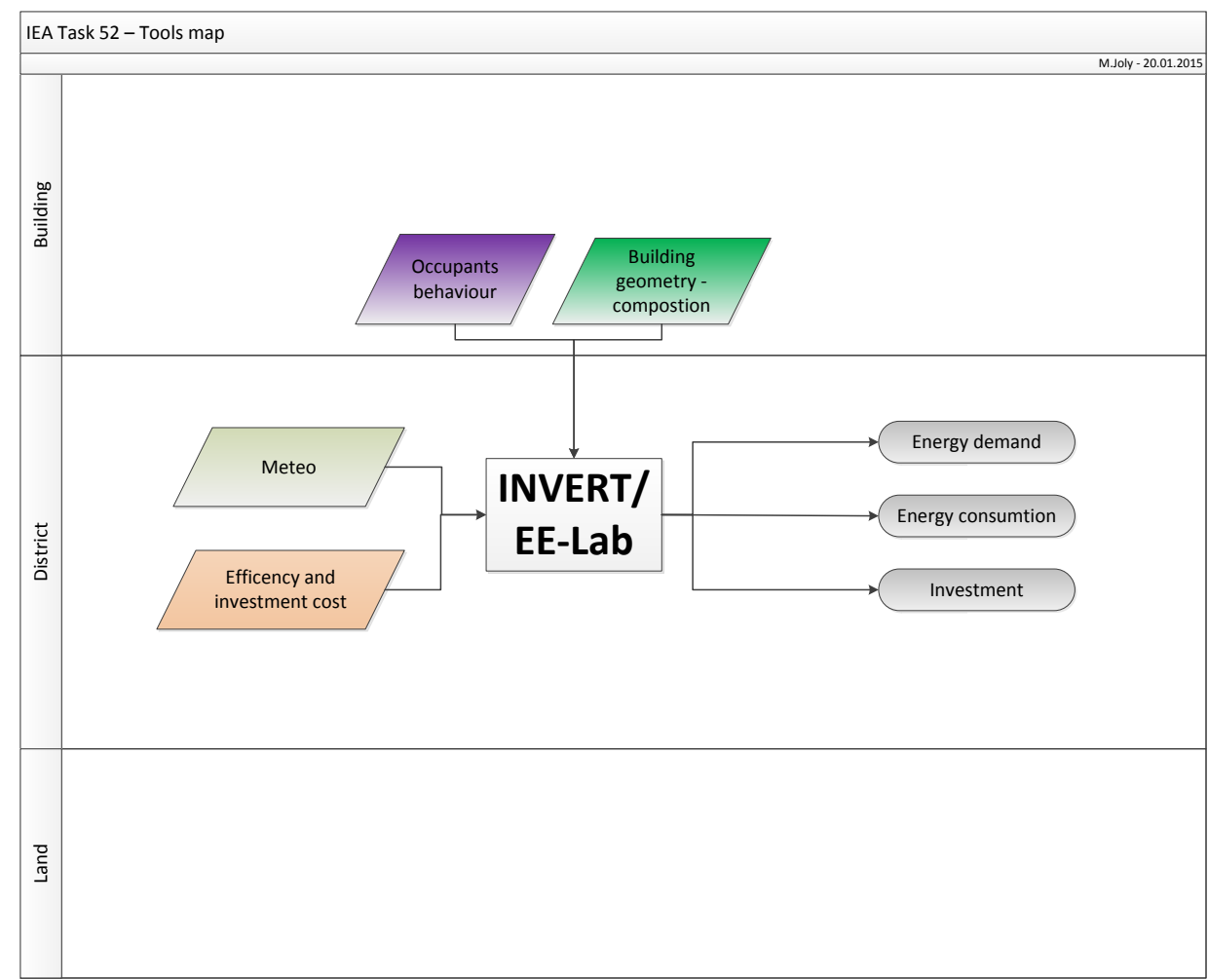

INVERT/EE-Lab (TU Vienna, Energy Economics Group)

Invert/EE-Lab is a dynamic bottom-up simulation tool and different scenarios can be simulated (price, insulation, behaviour). No GIS is used and the time resolution is one month.

Strength: this tool focuses on decentralized energy supply in the building.

This tool is already linked to an interface simulating the energy demand on an hourly basis. 


\subsubsection{REMOD-D}

Short description: Remod-D for Regenerative Energy Model for Germany. This software aims to optimize the cost of national energy systems under a given operational hierarchy.

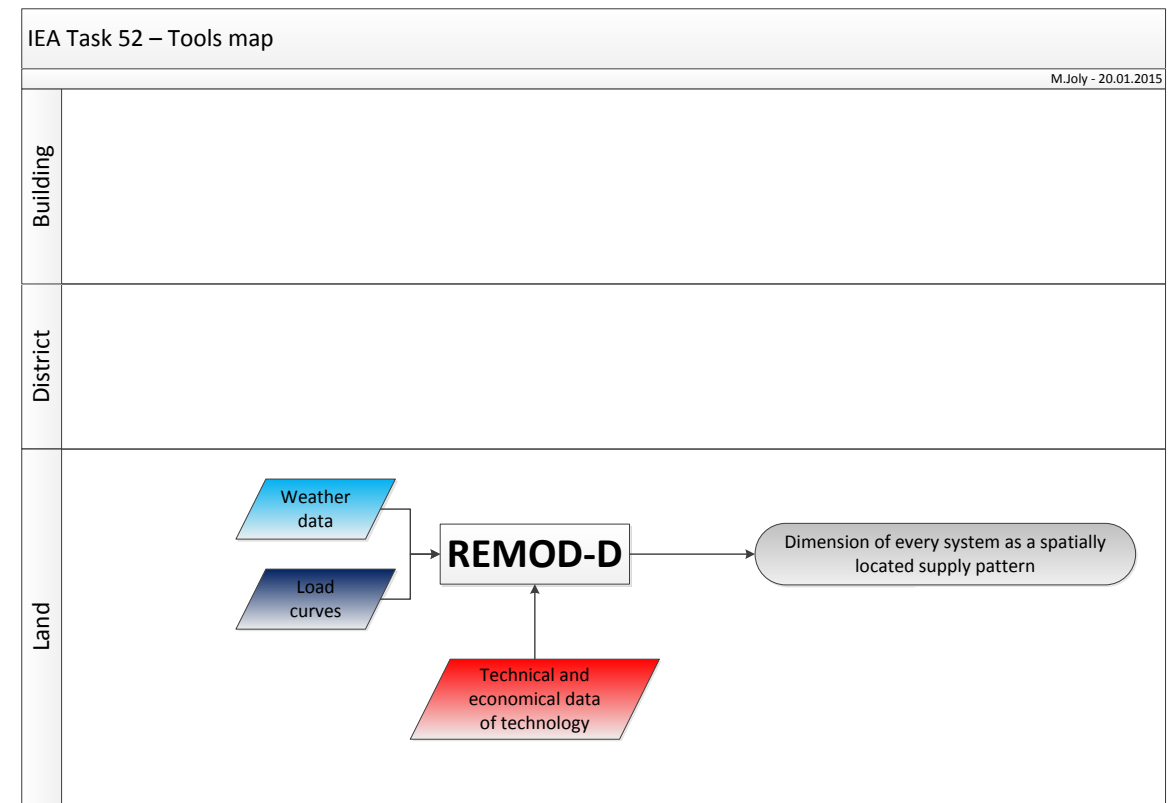

Remod-D (Fraunhofer ISE, DE)

Strength : this tool is able to manage optimisation of energy system at a land scale. Its time resolution is one hour. 


\subsubsection{KomMod}

Short description: This software aims to optimize the cost of urban/regional energy systems; simultaneous optimisation of structure and operation.

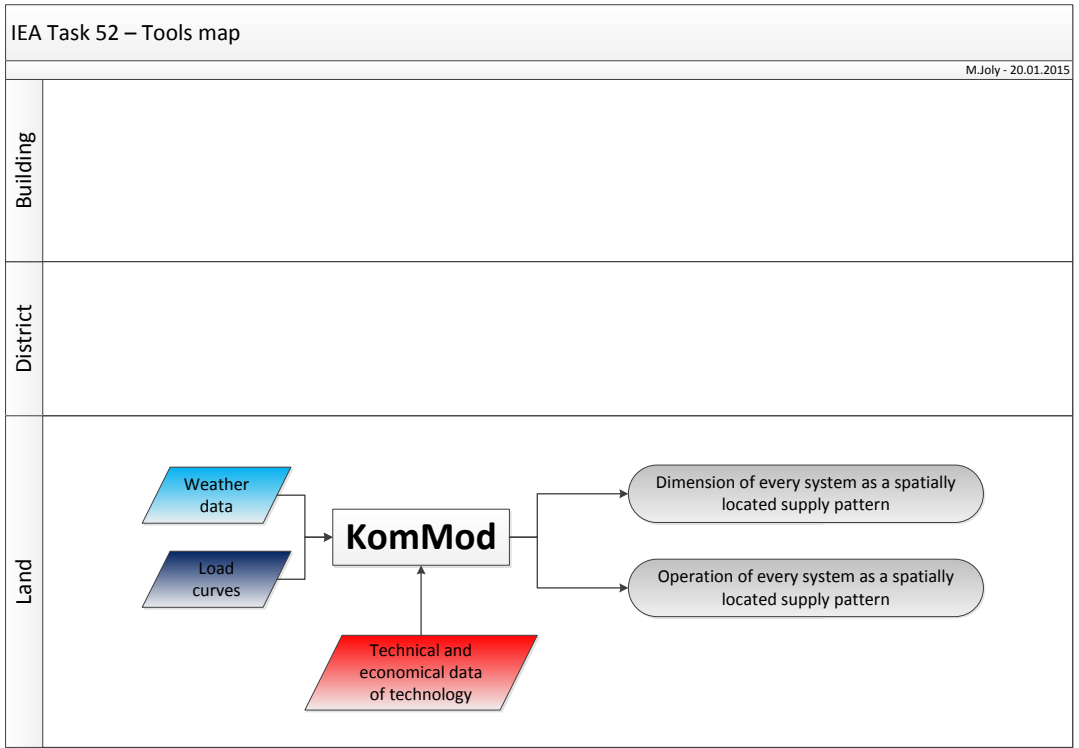

KomMod (Fraunhofer ISE, DE)

The main difference between this tool and the previous is the output. In this case, the operation of every system is given by the simulation. 


\subsubsection{Tools for thermal, electrical or hydraulic simulations}

\subsubsection{CitySim}

Short description: The CitySim software is aiming to provide a decision support to minimise the net-use of non-renewable energy.

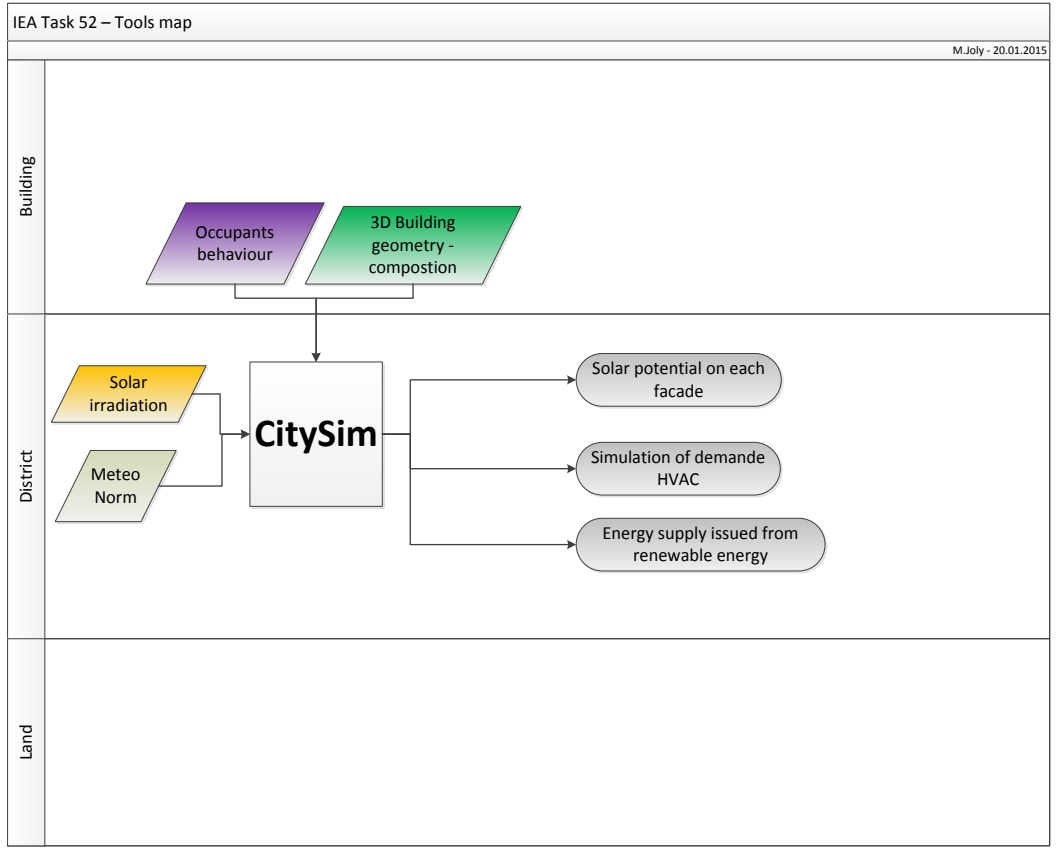

CitySim (LESO PB - EPFL)

CitySim is a software able to simulate the heat demand of a building. The occupant presence and behaviour is simulated by a stochastic model. Due to its 3D building geometry, the solar gains can be optimized. Sophisticated irradiation model is used considering the shading effect of the close horizon.

Strength: this tool calculates with a resolution of an hour the incoming sun radiation on building façade and roof. This hour by hour time resolution simulation is crucial for the evaluation of the heat flux and heat storage.

A developer team is working on this tool. The functionalities they plan to add are the following:

- Simulation of the production of thermal solar energy.

- $\quad$ Simulation of the solar thermal heat tank

- Simulation of the production of PV cells (already implemented)

- Simulation of the production of electricity by mean of wind turbine

- Simulation of the production and consumption of heat pump. 


\subsubsection{Trnsys 17.1}

Description: TRNSYS is an extremely flexible graphically based software environment used to simulate the behaviour of transient systems. While the vast majority of simulations are focused on assessing the performance of thermal and electrical energy systems, TRNSYS can equally well be used to model other dynamic systems such as traffic flow, or biological processes.

TRNSYS is made up of two parts. The first is an engine (called the kernel) that reads and processes the input file, iteratively solves the system, determines convergence, and plots system variables. The kernel also provides utilities that (among other things) determine thermophysical properties, invert matrices, perform linear regressions, and interpolate external data files. The second part of TRNSYS is an extensive library of components, each of which models the performance of one part of the system. The standard library includes approximately 150 models ranging from pumps to multizone buildings, wind turbines to electrolysers, weather data processors to economics routines, and basic HVAC equipment to cutting edge emerging technologies. Models are constructed in such a way that users can modify existing components or write their own, extending the capabilities of the environment.

After 35 years of commercial availability, TRNSYS continues to be a flexible, component-based software package that accommodates the ever-changing needs of both researchers and practitioners in the energy simulation community.

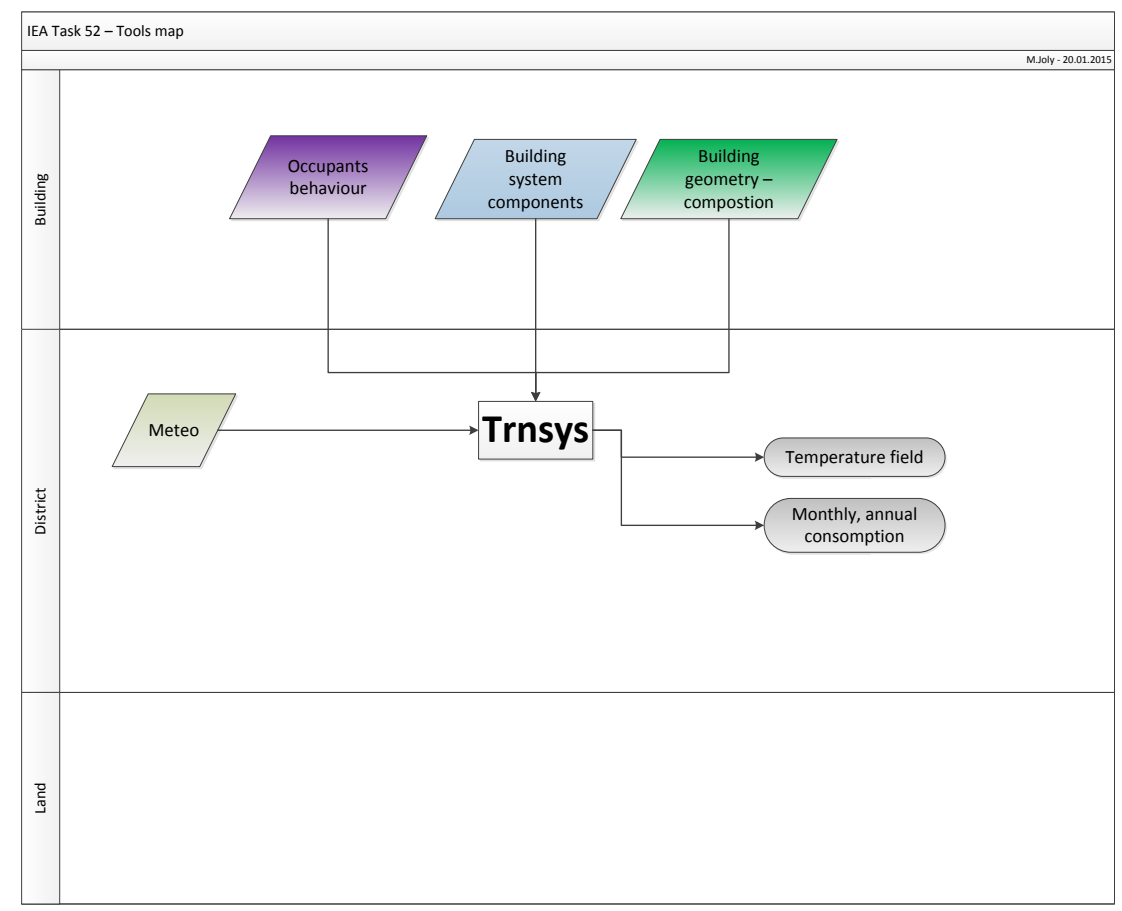

TRNSYS (University of Wisconsin, TESS, Transsolar)

Strength: very flexible tool to simulate complex situation on an hourly basis. The implementation of the model is quite complex. 


\subsubsection{B-Sol}

Short description: B-Sol is a tool helping at the conception of a room or a building in order to characterize its thermal response.

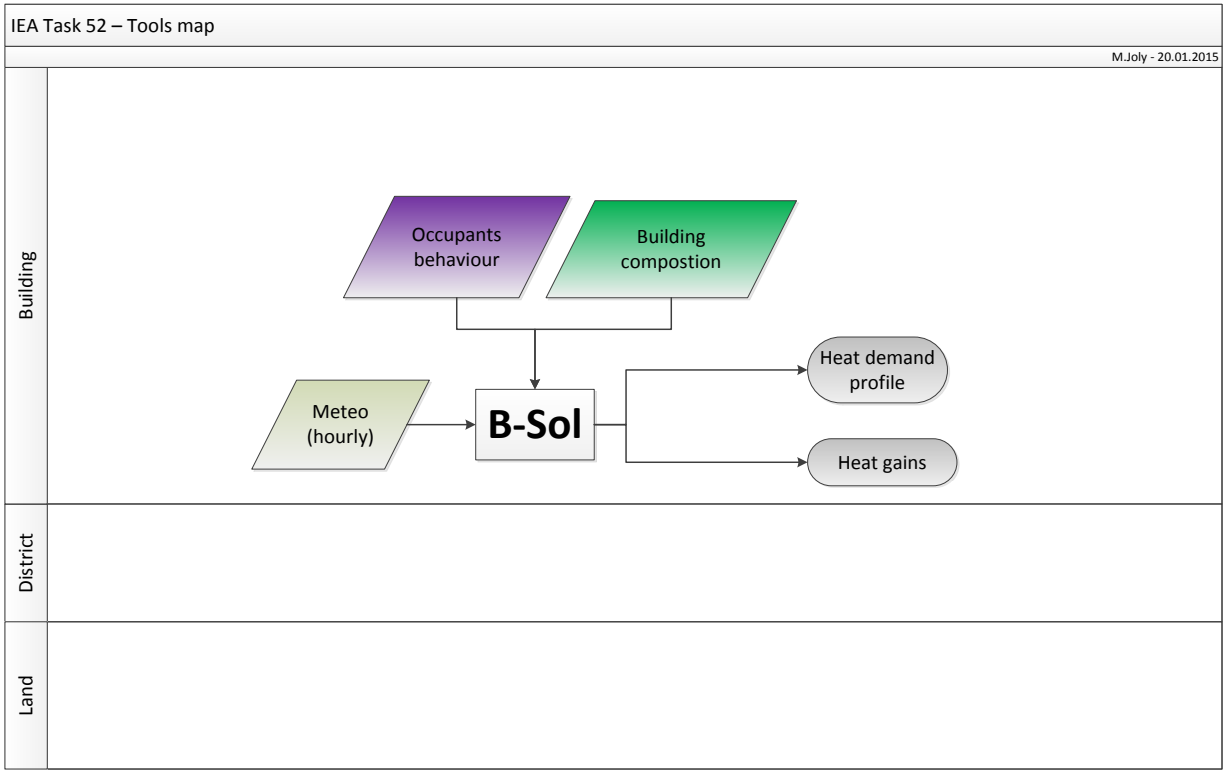

$B-S O l(H E S-S O)$

This is a building simulation tool to determine the heat losses distributions. The simulations are performed based on building characteristics and considering solar gains. The close horizon can be manually defined.

Strength: The software is able to manage an hour by hour calculation. The solar thermal gains are taken into account in the behaviour of the building. 


\subsubsection{Polysun}

Short description: Polysun is a simulation tool which can be used to design solar thermal, heat pump or photovoltaic systems as well as combined system.

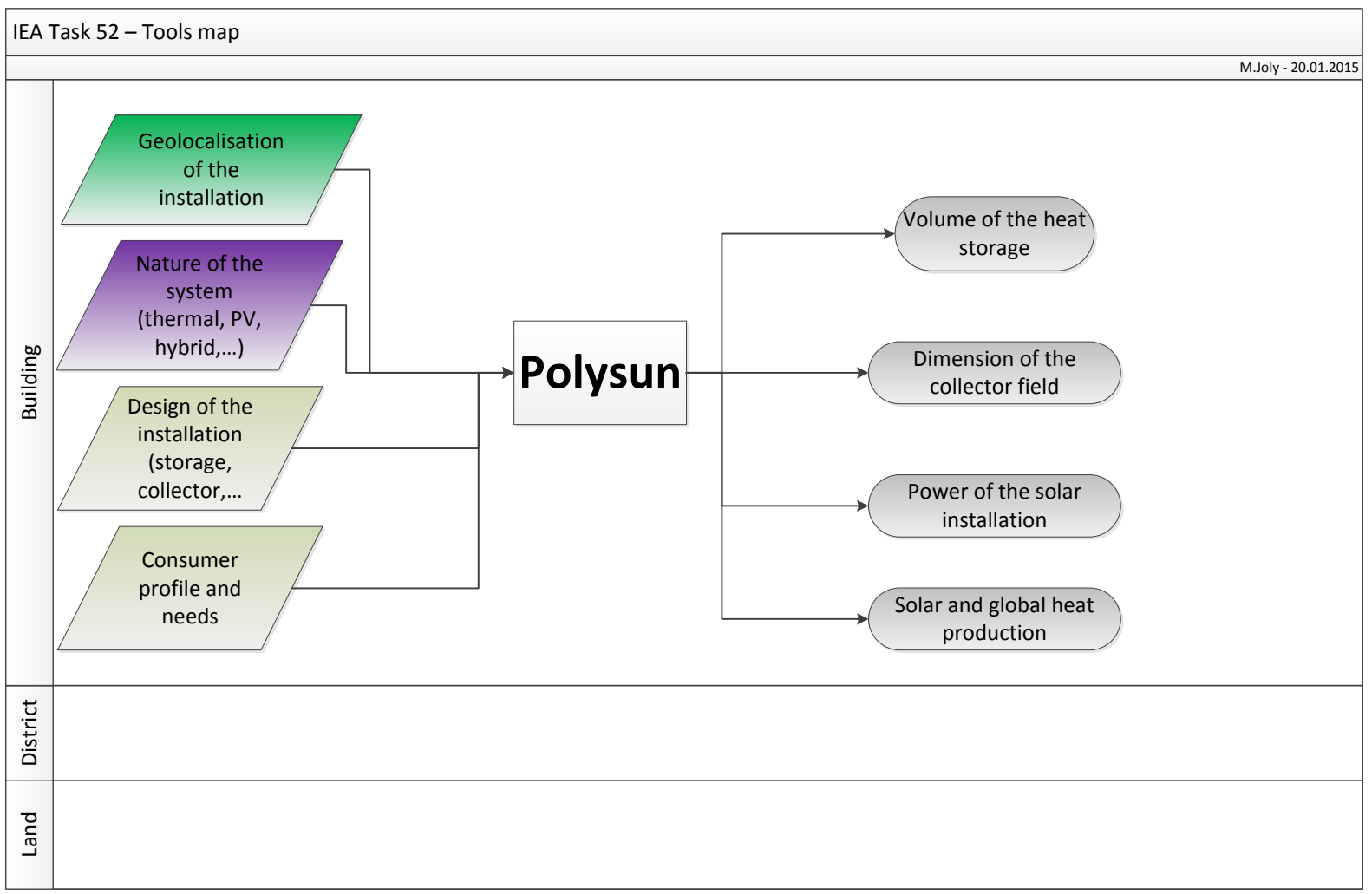

Polysun 


\subsubsection{SIMPLEX}

Short description: Simplex is a software dedicated to the calculation, design and optimization of district heating networks which allows technical (thermohydraulic) and economic network simulation on a minute-by-minute, up to hourly time base. The software is used for both the optimization of the operating performance of existing heating networks (e.g.: analysis of heat or hydraulic losses, parameter variations) as well as for the design of new or the extension of existing heating networks.

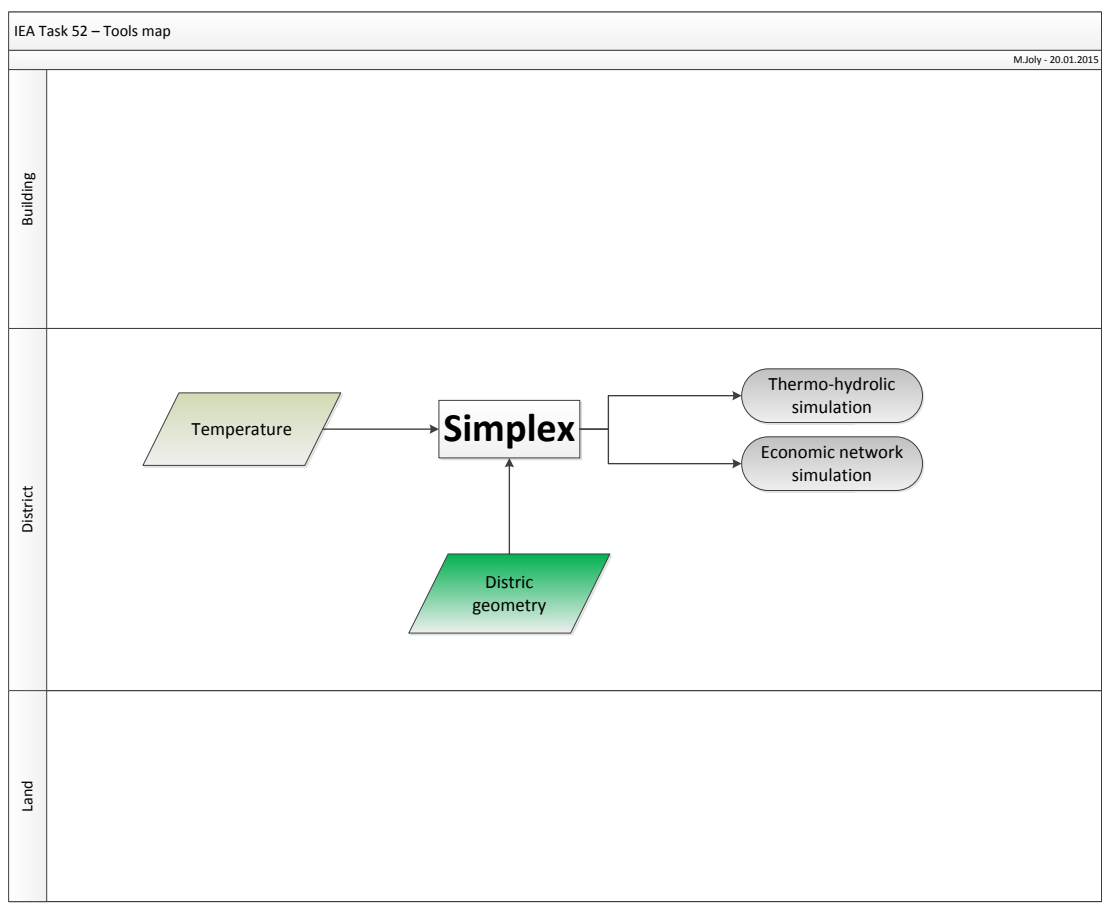

Simplex (Pink GmbH, Österreich)

Strength: the software is able to treat one building up to a city with 250-thousand people. The duration of the calculation time is three minutes up to one hour. 


\subsubsection{Tools for optimization}

\subsubsection{GenOpt 3.1.0}

Short description: GenOpt ${ }^{\circledR}$ is an optimization program developed for the minimization of a cost function that is evaluated by an external simulation program (e.g. TRNSYS). Independent variables can be continuous variables (possibly with lower and upper bounds), discrete variables, or both.

GenOpt has a library with local and global multi-dimensional and one-dimensional optimization algorithms, as well as algorithms for doing parametric runs.

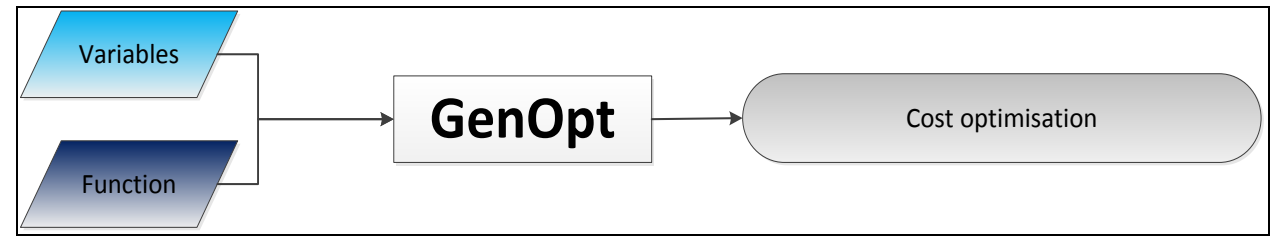

GenOpt (Lawrence Berkeley National Laboratory)

In our situation, GenOpt can be used to minimize many functions. It can be done for different scale such as a function linked to building consumption or in a city with district heating temperature. This tool is not sensitive to the question of time resolution.

Strength: this tool can be coupled to any simulation program. Using this tool with another one lead to a chain tool as it is the case in the next section. 


\subsubsection{TRNOPT 2.1.54}

Short description: TRNOPT is a tool that links a TRNSYS simulation model with the GenOpt program for optimisation (by minimisation of a cost or error function). TRNOPT may also be used to calibrate simulation results to the data from the actual system. TRNOPT is also known as the "TESS Optimization Library" and is part of the TESS Component Library Package (for TRNSYS).

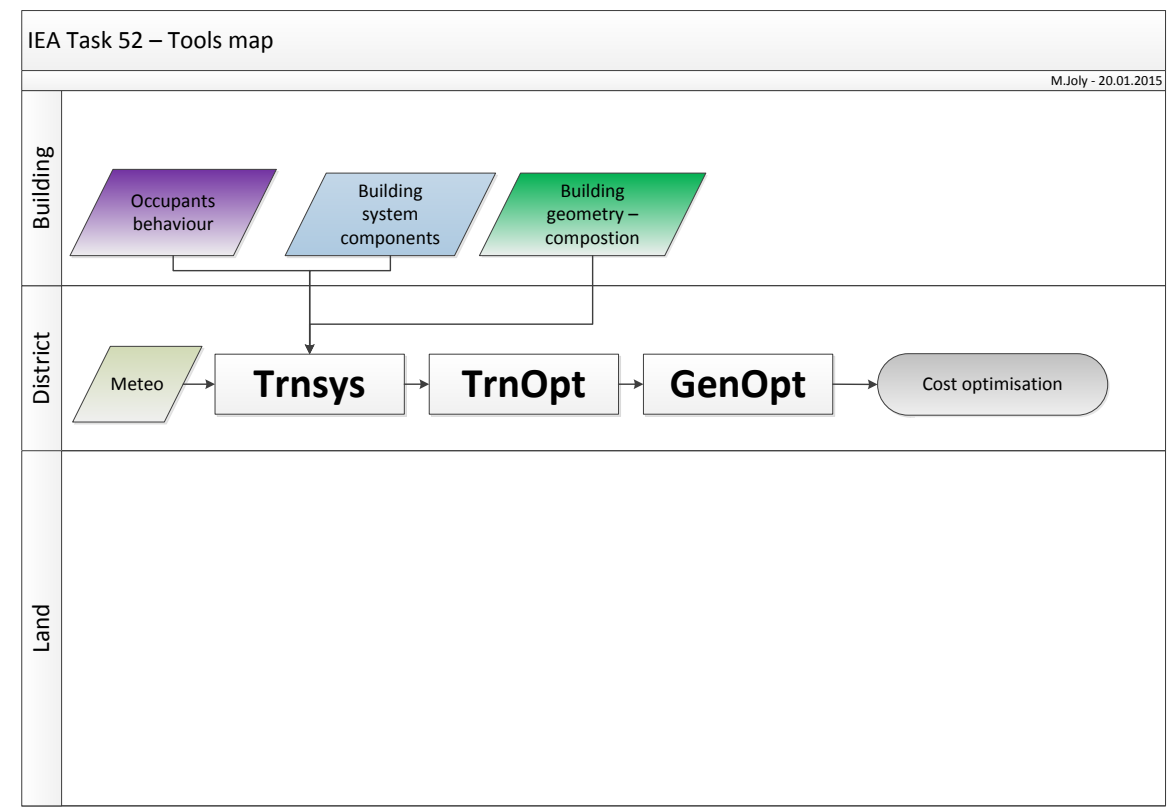

TRNOPT (University of Wisconsin, TESS) 


\subsubsection{Others : GIS, tool frameworks, co-simulation platforms}

\subsubsection{PlanETer}

Short description: GIS tool dedicated to elaborate territorial energy planning in 4 main steps: energy balances of actual situation, renewable resources quantification, future heat demands simulation and identification of energy supply scenarios.

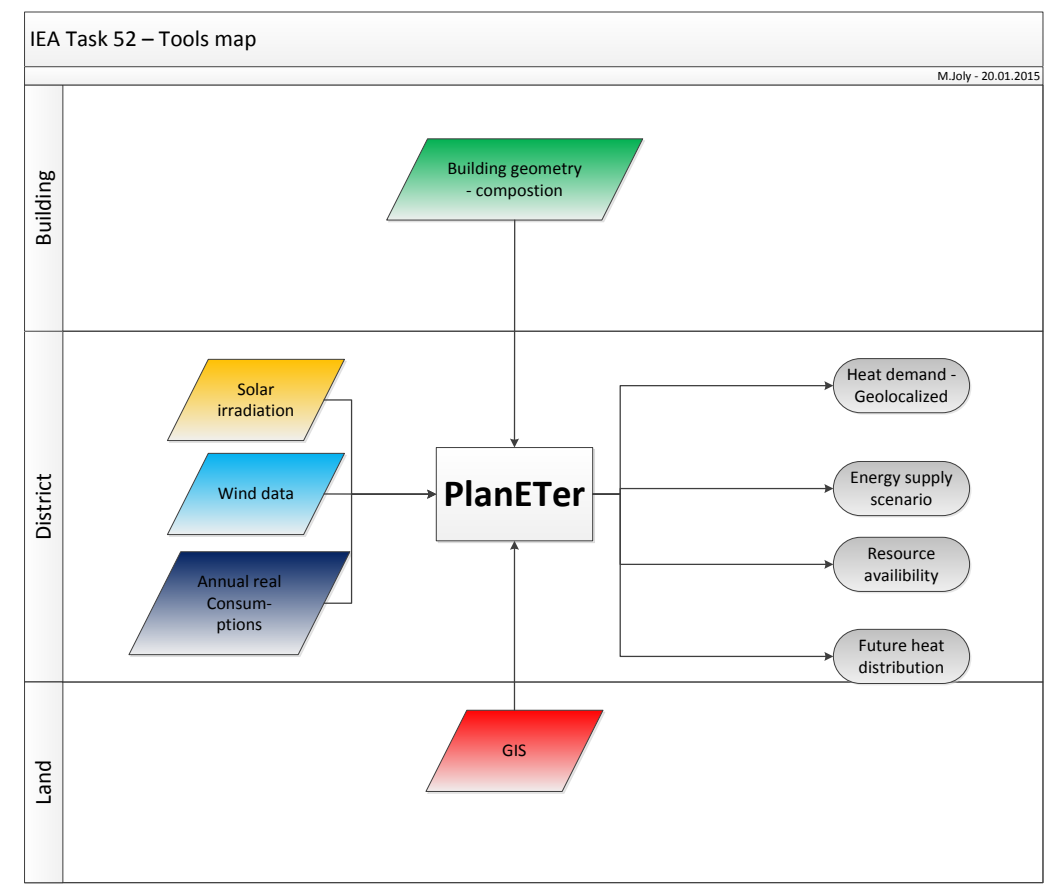

PlanETer (CREM), dedicated to future heat demands simulation energy supply scenarios

This tool developed by the CREM is built on the following methodology:

- Mapping of the territory with a GIS tool. The maximal resolution is the building

- Determination of the annual consumption of the buildings

- Evaluation of the future needs for heat

- Evaluation of the resources, renewable or not, available on the considered territory.

- Identification of the present and future synergies between the needs and the resources

- Elaboration of proposition for territory energy supply scenarios.

This tool is based on annual need and consumption. His strength is the possibility to elaborate energy supply scenarios at the scale of a district for municipalities. The thermal or electric annual solar energy potential can be given by this tool. 


\subsubsection{MEU}

Short description: The MEU GIS web-platform enables detailed monitoring and planning for both energy demand and supply at individual building and neighbourhood level.

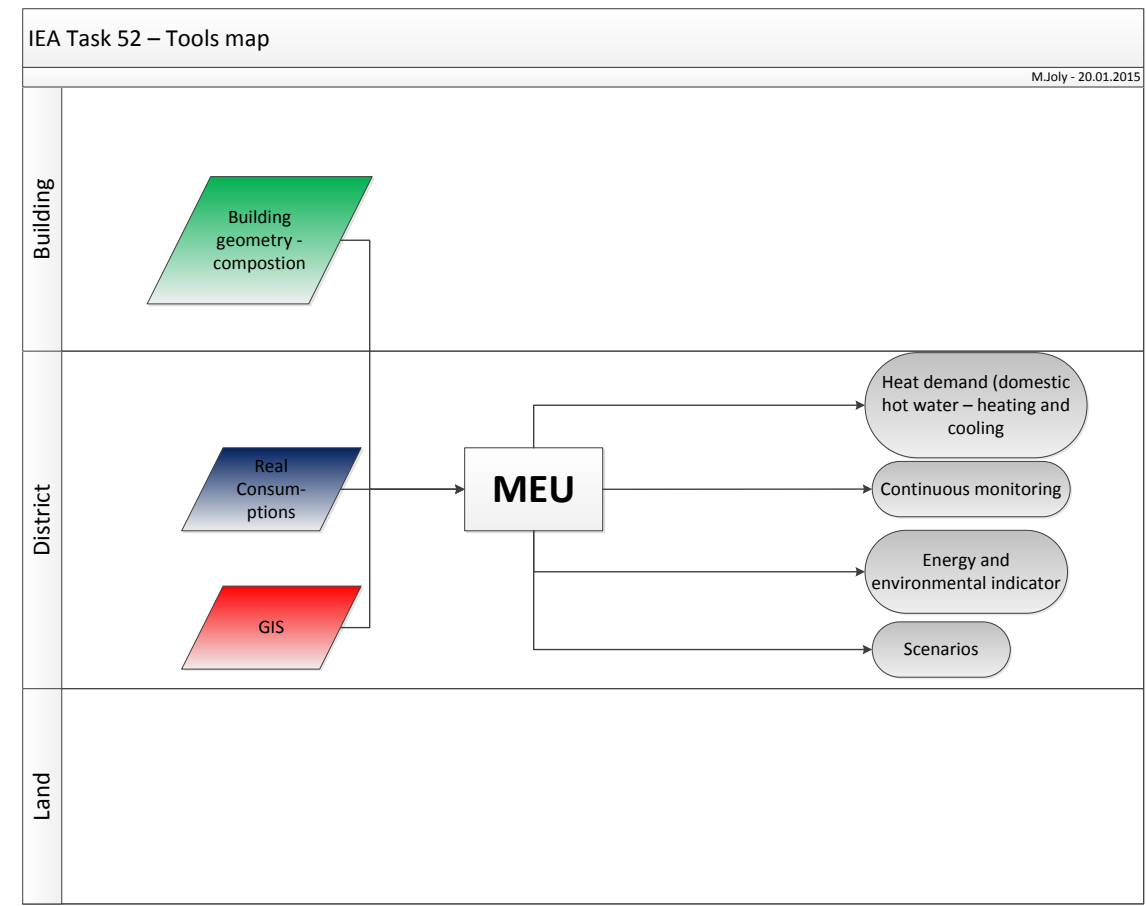

$\operatorname{MEU}(C R E M)$.

The MEU data basis is a powerful GIS tool to give a picture of the complex consumption of a city. The consumption of the buildings can be obtained either by using the real consumption bill or by using the CitySim simulation tool (EPFL thesis 6102, D. Perez, 2014).

Strength: This web tool is powerful to guide the energy planner in their future choices. In Switzerland, four towns are using this tool. 


\subsubsection{Smart Heat Design}

Short description: Optimization method for pre-designing the most exergyefficient systems in a given urban perimeter (districts)

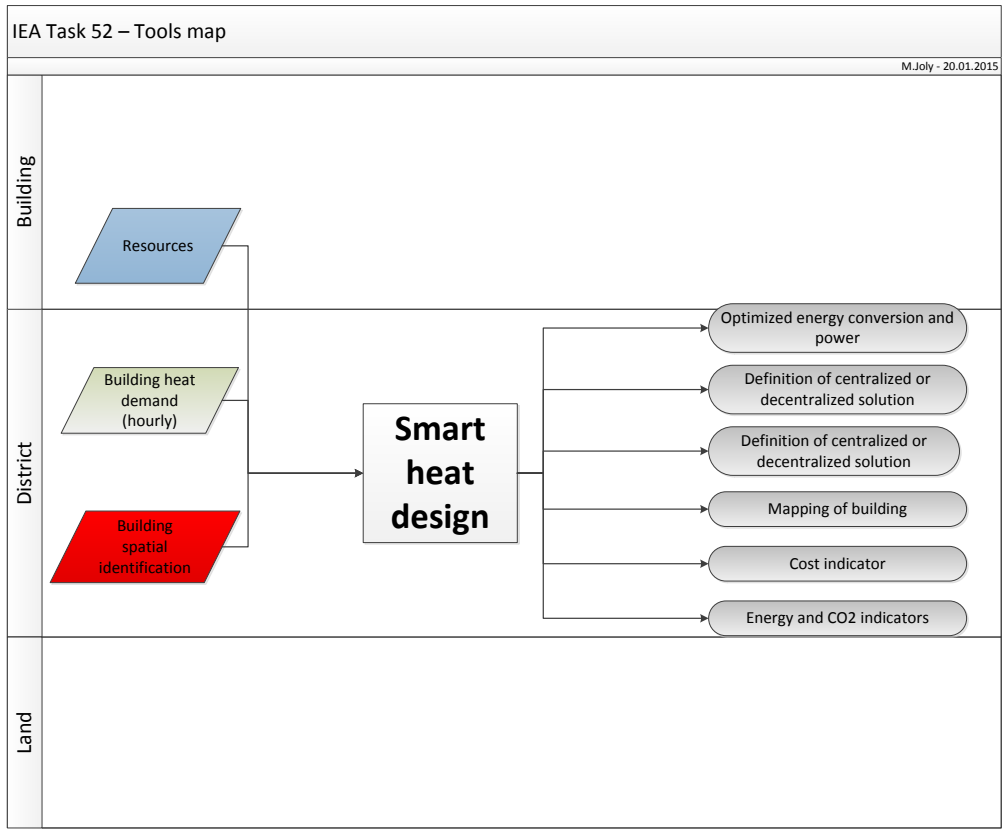

Smart heat design (CREM - EPFL - HES-SO)

Smart heat design is a software developed by the CREM. As well as MEU or PlanETer, this tool is based on a GIS data basis. Its goal is the optimization of the district heating.

Strength: This hour by hour calculating tool is able to optimize thermodynamics distributed network. In this network, producers and consumers are connected and decentralize production system can be implemented.

This tool is already a chain tool. 


\subsubsection{Time resolution}

Another goal of this survey is the description of the space and time resolution of each tool. In the following graph are represented the space resolution with respect to the left axis. The time resolution is given by the colour of the strip for each tool.

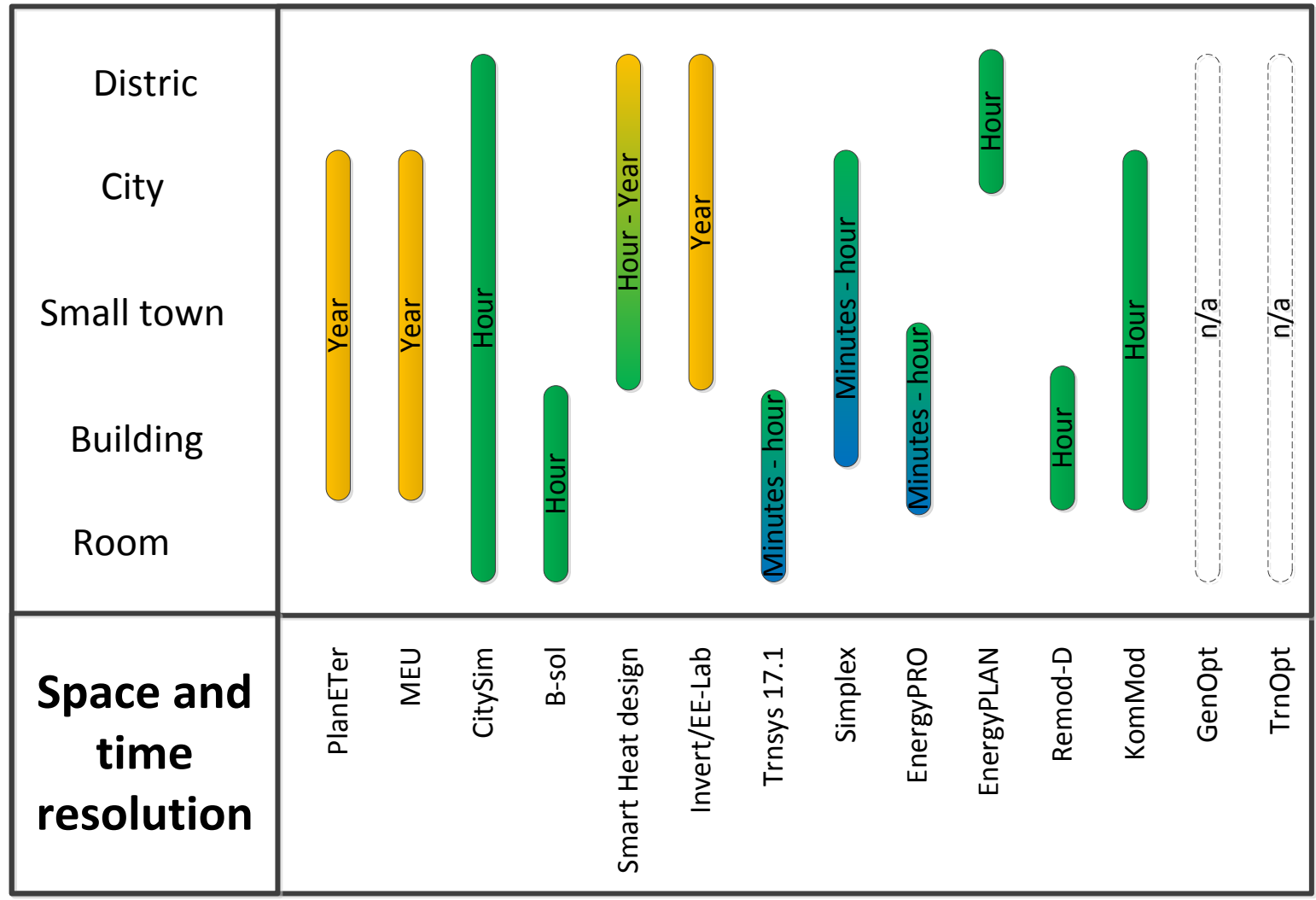

